


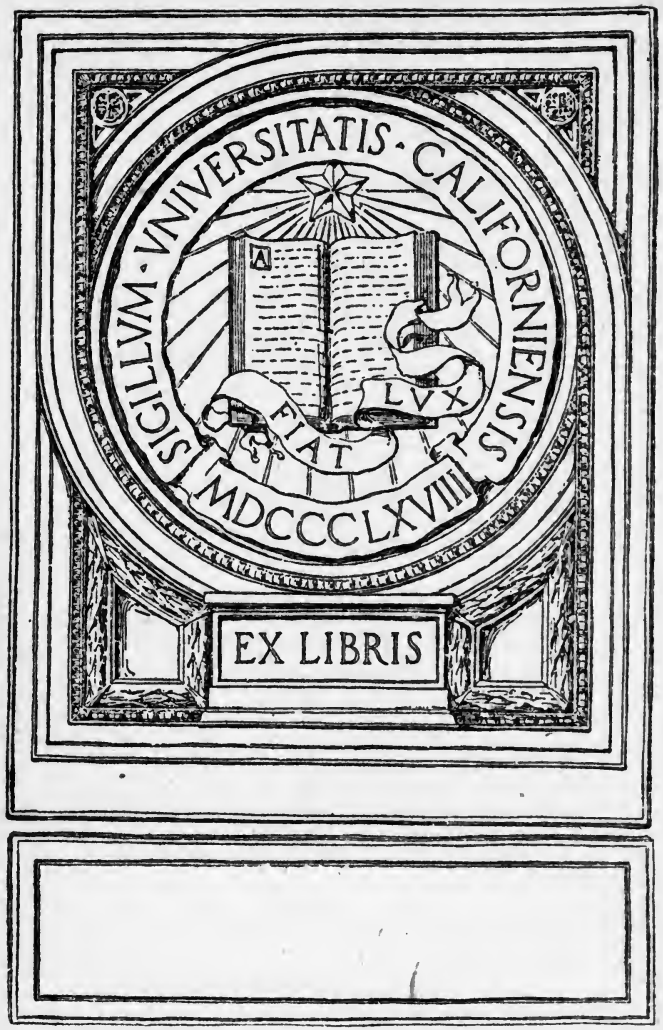


$\checkmark$

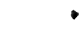

1 


\section{Digitized by the Internet Archive in 2007 with funding from Microsoft Corporation}


NERVOUS BREAKDOWNS

AND HOW TO AVOID THEM 
$$
\text { . }
$$ 


\title{
Nervous Breakdowns and How to Avoid Them
}

\author{
BY \\ $\begin{array}{ll}\text { CHARLES D. MUSGROVE } & \text { M.D." }\end{array}$
}

NEW YORK

FUNK AND WAGNALLS COMPANY 


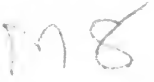

BIOLOGY LIBRARY

Bristol, Eng.: J. W. Arrowsmith Ltd., Quay Street. 


\section{CONTENTS.}

CHAPTER I.

BREAKDOWNS

The shock. The kind of person most liable. The nature of breakdowns. Neurasthenia, the two types.

CHAPTER II.

THE DANGER SIGNAL

The signs of a breakdown. Each individual his or her own standard. Breakdowns preventable.

CHAPTER III.

HEALTH

Health, not illness, the standard. What health is. The motor-car. The human machinery. Interplay between the various parts. Combustion-Ashes or waste matter, and how got rid of. The nervous ramifications. Starvation and poisoning. Compensation. Cause of breakdown. The remedy.

CHAPTER IV.

THE VAlUe of health .

Happiness. Efficiency of work.

\section{CHAPTER V.}

REWARDS AND PENALTIES

The health seeker.
The reward of care. The inevitable penalty. Nature's disregard of motives. The laws of health. Food, fresh air, exercise and rest. 
The locomotive stoker. The human furnace: (I) The sort of food to take, (2) The amount necessary, (3) How to take it, (4) When to take it.

CHAPTER VII.

\section{WHAT TO EAT}

Differences of constitution. Likes and dislikes. Good and bad cooking. Proteids or meat foods. Meat and gout. Starchy foods. Bread. The saliva. The slow poison of dyspepsia. Eggs, Soups. Fat. Milk. Sour milk treatment. Sauces. Hunger the best sauce. Tea. Coffee. Alcohol.

\section{CHAPTER VIII.}

HOW TO EAT FOOD

Mastication. The importance of sound teeth.

CHAPTER IX.

HOW MUCH FOOD TO TAKE

Personal requirements. As a rule people eat too much. Dangers of excess. Diet at middle age. Diet for the obese.

CHAPTER $\mathrm{x}$.

WHEN TO TAKE FOOD

Punctuality essential. Interval between meals. The digestive troubles of a hundred years ago and to-day.

CHAPTER XI.

FRESH AIR

The human furnace always alight. Fresh air and the nervous system. Fresh air in the home. The two-edged sword. Consumption. Common colds. Sitting-rooms and bedrooms. How to obtain fresh air without draughts. Breathing through the nose. Breathing exercises. Cleanliness. Tidiness. 
Overwork or want of exercise ? Exercise at middle age. Value of exercise. Regularity. Violent exercise. Cramp. Outdoor games, walking, cycling, etc. The pavement walk. Starting indoor exercises. Cautions as to dumb-bells, etc. Object of exercise. Swedish drill. Imitation of games. Massage.

\section{CHAPTER XIII.}

BATHS AND BATHING

Hot baths. Temperature. Effect on various ailments. How they act. Cold baths. Outdoor bathing. Turkish baths.

\section{CHAPTER XIV.}

REST

The spirit of unrest. Modern life. Periodic rest. What rest is. Recuperation. Power of self-repair in the body. Bodily rest, and how obtained. Rest of mind. Change is rest.

\section{CHAPTER XV.}

SLEEP .

Beauty sleep. Ebb and flow in human system. Remedies for sleeplessness.

CHAPTER XVI.

HOLIDAYS

The annual holiday. Where and how to go. Continental trips. Preparations for a holiday. Diet and exercise. The restful holiday. Tired eyes. The return.

\section{CHAPTER XVII.}

RECREATION, HOBBIES

Games and hobbies. Hobbies and homc life. Hobbies in the prevention and treatment of breakdowns. Choice of a hobby. 
Necessity for it. Mental exercise. The cry for young men. Conditions of work. Before. Bad effect of hurry. During. Hygiene. Noises. Telephone. Bad light. Midday rest. Meals. Nature of work. Working against time. Public work. After. Exercise. Rest. Recreation.

CHAPTER XIX.

WORRY

Worry, not work, that kills. The effect on the mind. Worry and neurasthenia. How to avoid worry. The influence of the body on the mind. Anticipation. Beset by work. Stimulants. Overwork versus worry. Hobbies as a remedy.

CHAPTER $\mathrm{XX}$.

THE STRONG MAN .

What strength is. Find out the weak points. Know your own temperament. Adjusting the mind. The secret of preventing breakdowns. 


\section{Nervous Breakdowns and}

How to Avoid Them.

\section{CHAPTER I.}

BREAKDOWNS IN GENERAL.

AN express train was on its way from London to Edinburgh. It was running at sixty miles an hour, and the passengers, as comfortable as if they had been sitting in easy chairs by their own firesides, were engaged in reading, sleeping, talking or looking out of the windows. Not a thought of any impending trouble crossed their minds.

Suddenly they felt a jar, followed by a jerk ; the train slowed down, and within ten seconds had come to a standstill. Then there was general commotion, and heads appeared at every window, to see or inquire what was the matter. There was no station in sight, and no signal against them. Yet that train, which a few moments earlier had been speeding along in all its power and pride, had come to a dead stop.

And when those passengers alighted from their compartments and began to investigate matters, they were no nearer a solution of the mystery. 
The train had not left the rails, the carriage wheels were intact, the engine was undamaged, the fires burning and the steam up. Yet something had happened, and whatever it was, it had rendered that train a useless mass of timber and steel for the time being. It was still a fine thing to look at, but as a means of locomotion it was of no more use than a child's toy would have been.

Yet, great as was the trepidation of those passengers, it was nothing to the shock experienced by the man who in the prime of life, and perhaps just when he bids fair

The to reach the heights towards which shock. he has been striving with all his might for long years, suddenly finds that he is incapable of the very work of which he had prided himself he was master.

It may be that he has toiled since youth in order to attain a certain position, and just when it comes within his reach his nerve fails him, and he cannot put out his hand to take it. The energy and ability which have carried him so far along the road fail him at the critical moment.

Or it may be that he has struggled through laborious days and nights and amid many disappointments for fame. Just as he is about to realise his ambitions he breaks down, and becomes an embittered misanthrope. The genius which has enabled him to climb so many rungs of the ladder becomes inert, and he cannot mount the last step.

Another spends his life in a good cause- 
philanthropy, religion, public work of any sort. At the very time when, by the experience he has gained, his years of greatest usefulness stretch before him, he is cut off, incapacitated by nervous debility.

And it is not only men who go through this experience; the same may befall women. Often has it happened that a woman has devoted herself so assiduously to the care of her family, regardless of her own disturbed meals and broken rest, that just when her children needed her most of alland that is when they were growing up-her strength has failed her and she has become an invalid.

The lamentable part about breakdowns is the fact that they attack those who can least be spared. It is not the clodhopper, the navvy or the labourer, the careless or the incompetent, who suffer from them. On the contrary, we meet with them among skilled workmen, business men of the greatest ability, professional men of the highest acumen and experience. The former can be replaced, whilst these others have carved a niche for themselves which no one else can fill.

It is the natures of finest fibre which accomplish the most, and it is they who are most liałle to give way beneath the strain. A common mug may fall to the ground unharmed, where a piece of costly china would be smashed to atoms. When a masterpiece of art is lost or stolen, the whole nation grieves after it. How much more so when a man of repute, either in great ways or small, is invalided and his services lost to the world. 
There is no doubt that breakdowns constitute one of the most momentous problems of the day.

We hear of them on all hands, in The problem different guises and under various of the day. terms. Go into any company you like, and it is safe to say that before many minutes have passed matters of health will be under discussion, and oftentimes they are nerves or breakdowns in some form or other.

It is only natural, perhaps, that this should be so. Yet too frequently the only result of these aimless conversations is to accentuate suffering, instead of leading to the acquisition of any useful information which might help to relieve it. Unfortunately, the general public seems to have made up its mind that nervous disorders are an inevitable concomitant of modern life. They fear them just as they fear influenza, wondering who will be the next to be attacked.

Yet there is no comparison between the two complaints. For the one is due to a germ which pounces upon the good and the bad, the wise and the foolish, the thoughtful and the careless, with absolute impartiality; whilst the other is brought about by a number of conditions, all associated with our mode of life, for which we are responsible, and over which we have a vast amount of control.

Influenza comes like a bolt from the blue, attacking its victims with disconcerting suddenness. To be sure, breakdowns may appear, in many cases at least, to come in a fell swoop; but what seems so abrupt and unlooked for is usually the climax to a long-continued process 
of undermining, like the collapse of a house, which has succumbed to the ravages of time. Yet the events which have led up to it may have been spread over a large number of years.

Occasionally we hear of someone who has been disabled all of a sudden by some definite form of ailment, paralysis, cancer or heart The nature disease, it may be. Such cases of a break- are, however, the exception, and down. they are not the breakdowns with which we are now concerned. In the great majority of instances " breaking down" is the final stage of a long process of " running down." There is as much difference between the two classes of cases as between an engine which has come to a stop because a wheel has come off or a connecting-rod broken, and one that has become useless owing to neglect or prolonged wear and tear.

The period of running down may last for months or years, and it is characterised by various symptoms, physical and nervous. It is the former which are at the root of the matter, but the others predominate more and more, until, when the final breakdown occurs, they overwhelm the bodily symptoms altogether. On this account it is usually designated by terms expressing this nervous element: nervous exhaustion or debility, neurasthenia or simply nerves. Yet all these are only different phases or stages of the same complaint.

What, then, is the nature of this complaint? It is one that has suffered from much 
misapprehension, chiefly through the use of the term "nervous exhaustion." This phrase has given rise to an impression in the lay mind that there is a limit to the nervous force with which human beings are endowed, as though each one started with a certain quantity which must come to an end sooner or later.

This idea is a fallacy, for nervous energy is in process of being manufactured every hour we live. And Nature stores up out of this supply a reserve from which we may draw in any emergency that may demand a special output.

This reserve fund is constantly varying. It is replenished during the hours of sleep, it is called upon during the period of wakefulness. Sometimes an extra call has to be made upon it. A woman may have her night's rest broken, or she may even lose her sleep altogether for several nights in succession. Or a man may have a sudden stress of work which cannot be avoided. Then the reserve may be depleted, but that does not constitute a breakdown. If care is taken to ensure sufficient rest afterwards, the surplus is regained. It is only when a constant drain is put upon it that serious damage results.

And in many cases of breakdown the question of exhaustion plays no part. For most neurasthenics show no loss of

The two energy; in fact, many of them types. exhibit an increased output. The crux of the whole matter is not exhaustion, but a loss of control over the nervous forces. This loss may show itself in two distinct 
ways. It may either prevent the energy from manifesting itself, or it may discharge it in a spásmodic manner.

One market-day, in a country town, there were two horses, both of which, so far as their utility was concerned, were equally inefficient. Yet neither were lacking in energy. The one was excitable, plunging about to the danger of the public, and in any direction except the right one. The other was, on the contrary, perfectly quiet, standing harnessed to a vehicle, but unable to move it. This animal had strength and nerve force in plenty, yet it was incapable of making use of it. For a drunken ostler had harnessed it the wrong way round, with its head towards the cart.

The same types can often be recognised in those who suffer from nervous breakdown. Some patients become fidgety and restless, rushing about from pillar to post, worrying their employees or their fellow-workers, and fussing around in the home until the rest of the household dreads the sight of them.

Others are precisely the opposite of this. They become moody and taciturn, or disinclined to meet their friends or take part in a conversation. A woman will sit by herself most of the time, not caring even to have her children about her. A man will have a difficulty in making up his mind not only on important points of business, but it may be on the most trivial matters. $\mathrm{He}$ begins to look at his work as stupidly as the aforesaid horse stared helplessly at the cart he was supposed to pull. 
Where does the fault lie ? Not in too much energy or too little, but in some derangement of the system, whereby the patient's faculties either go astray or are rendered inert. And in order to discover the real source of the mischief, it is necessary to look, not at the climax, but farther back, through a long sequence of events which have been leading up to it. 


\section{CHAPTER II.}

THE DANGER SIGNAL.

IT will naturally be asked by what sign is a man or woman to know when they are threatened with a breakdown.

By no one sign in particular. One cloud does not make a wet day. It is only when other clouds begin to gather and we feel a certain change in the atmosphere that we surmise that rain is coming. The signs which warn us of the approach of a storm are almost too indefinite for words.

The symptoms by which a man is led to think he is on the verge of a breakdown are equally vague. That is what makes thern

Signs of a all the harder to locate and to bear. breakdown. If he has sciatica, pleurisy or a gumboil, he can speak of his ailments and tell people what is the matter with him. The neurasthenic has not even this consolation. His symptoms are so indefinite that he can scarcely find words in which to express them; if he could do so, he would shrink from mentioning them for fear that his friends would laugh at him.

For it must be understood that neurasthenia is a very different matter from hysteria or hypochondriasis. The hysterical subject craves for sympathy, and will imitate all sorts of ailments 
in order to secure it. The hypochondriacal imagines he has all manner of diseases and loves to talk about them to anyone who has the patience to listen to his tale of woe.

The neurasthenics are the very opposite of this. They are usually people of refined susceptibilities, sensitive about themselves and their feelings. They have, therefore, to bear their burden alone. They see the clouds gathering on their mental horizon and their sky getting darker and darker. The future becomes laden with foreboding, and all around there is the presentiment of a storm that is about to break. Often they keep their feelings to themselves, until at last these become of such intensity that they can no longer be hidden. Such persons often welcome a definite illness, if only because it gives them something unmistakable to speak about, affording them the opportunity of calling in the medical aid of which-quite wrongly, be it observed-they had previously been ashamed to avail themselves.

We are sometimes told that headache, giddiness, pains in the region of the spine, weak digestion and a host of similar complaints are preliminary signs of oncoming breakdown. Yet, whilst they often accompany the latter condition, they are also significant of many other ailments, which have nothing to do with it. Sciatica may be the result of a chill, spinal pains of an influenza cold, whilst headache may be due to biliousness, faulty eyesight or a variety of other conditions. The fact that we suffer from any one of them does not imply that we are threatened with a 
breakdown. For all that, it is not well to neglect these complaints, for it is certain that if we have any tendency to nervous trouble they will hasten it on.

To suggest, however, that such symptoms are preliminary to a nervous collapse would be to inspire, in the minds of many people, a sense of terror which would precipitate the very disaster we are anxious to avoid.

One thing, however, it is necessary to emphasise. If any symptom of this sort-and the remark applies especially. to headaches-is found consistently to come on during the hours of work, alleviating after the work is over for the day, it should be taken as a danger signal. For when anyone's occupation brings on a headache, the complaint is much more likely to be due to some weakness of the nervous system than to any fault in digestion or eyesight. And the same applies to many other symptoms also.

The phenomena I am about to describe are those suggestive of nervous weakness, and any man or woman who recognises themselves in the picture I shall attempt to draw had better take warning. They need not alarm themselves unduly, but they will be well advised to pull up short.

There is one point which must always be kept in mind. It does not follow that because a person is easily tired, or is irritable or depressed or dreads any ordeal awaiting him, or is nervous in any direction, that he or she is drifting towards a breakdown. It is when people who have previously been free from such weaknesses find that 
they are acquiring them that they must face the fact their nervous systems are on the down grade. Each individual must be taken as his or her own standard. What is natural for some would be unnatural for others. A person is ill when he falls below his own level of health, either of body or mind. The various signs of neurasthenia or breakdown depend, not on comparing a man with anyone else, but in measuring him by his former self.

One of the most constant symptoms is a gradual decline in strength, either of body or mind, without any organic disease to acLoss of count for it. If a man whose heart, strength. lungs and kidneys have been proved sound begins to suffer from fatigue after an amount of exercise such as he would not previously have noticed, everything points to the fact of its being the result of some impairment in his nervous system. More particularly so if the tiredness is of an unpleasant nature. There is a delightful form of fatigue and there is a painful one. There is nothing more enjoyable than the gentle aching which a healthy man feels as he stretches out his limbs in a comfortable chair after a good day's walking, shooting, golf or whatever else it may have been. He feels, in mind and body alike, a delicious sense of half-sleepy lassitude, which affords to a higher degree than anything else a sense of repose and well-being.

That is very different from the weariness that dogs a man's footsteps wherever he goes, or is even with him during his sleeping hours, so that he rises 
in the morning more tired than when he lay down. When that happens something in his organisation has gone wrong.

Equally significant is the langour that attacks people when they are following their daily avocations. Of course, it is natural that as people grow older they should find themselves less capable of exertion than they were in their younger days. Most persons over forty years of age have to take things somewhat more quietly than before. They are not so well able to run, and perhaps have to walk more deliberately, but that is very different from feeling fatigued when there has been no justification for it. Yet even that is not a matter of such gravity as when a man who has taken a keen interest in his daily work, of whatever sort it may be, discovers that it is becoming more and more of an effort. Or it may be a woman, who finds her household duties, which had hitherto been a pleasure to her, becoming a bugbear. And when anyone, either man or woman, begins to look forward habitually with dread to the work of the following day, their health is in sore need of attention.

Yet in most cases all that they do is to reproach themselves for their indolence and apply themselves to their duties still more Worry. assiduously, with the usual result that they worry themselves and everybody else. And the harder they try the worse things get, until at last the work in which they had taken such a pride becomes a nightmare to them. They begin to shrink from the thought 
of it, yet it forces itself continually upon their notice. Perhaps even the evenings, which should bring a sense of refreshing and repose, are spoiled by fretting over the events of the day that is gone and worrying as to the work of the morrow; the housewife in trepidation as to her duties in the home, the workman to his job, the commercial man to his business, the parson to his next appearance in the pulpit.

The result is that in many cases the work suffers.

Worry and anxiety are the common lot of mankind, at any rate in this age of stress and competition. Yet it is not the common cares of life which have a detrimental effect on the human system, but this useless, exaggerated vexation of spirit. When a man has lost the power of leaving his worries behind him, it is time that he began to take heed, for sooner or later they will affect his work. If he allows himself to drift, wasting his energies by futile struggling against his own disabilities, his mental faculties will begin to show signs of wear and tear.

It may be that his memory will play him tricks, words and facts failing him at the critical moments.

There is no surer sign of

Memory. neurasthenia than when a man who has always been a ready speaker, begins to hesitate for words in which to express himself. The worst symptom of all is when people noted for their firm, decisive characters find themselves unable to make up their minds, either on some subject of general interest or on points connected with their own pursuits. 
An even worse phase of fatigue is that which intrudes upon the hours of recreation. It is bad enough for people to become unduly

Pleasures tired at their work; it is worse when pall. they become tired at their play. When amusements cease to afford any gratification, and people lose interest in their favourite hobbies and pursuits, their nervous systems are perilously near a breakdown. 'This weakness has passed into a further and a more serious stage.

Then social intercourse is apt to weary them. They find a difficulty in concentrating their attention on a conversation, especially if the subject under discussion happens to be one demanding close attention. Sometimes, however, even an ordinary chat will tire them out. It may be that they are unable to read the lightest literature, the effort to follow a story proves too much for them.

In consequence of all this, they fall into a sad plight. For not only are they deprived of the solace of amusing themselves, but

Change of their friends are apt to fight shy disposition. of them. When people get into this state they become ultrasensitive, and see slights and insults where none were meant. They are liable to lose their sense of humour too, and can neither appreciate nor take a joke. After that, it is not long before they see their friends deserting them, which means that they are driven back upon themselves.

That; on the top of everything else, depresses 
them, and they worry still more over unnecessary trifles. Probably they become sleepless, and that will haster on as nothing else can do the inevitable climax.

Irritability of temper is often one of the first signs of this malady, not of course in those who are naturally quarrelsome, but in those who have hitherto been of a genial, companionable disposition. In fact, change of disposition is one of the most significant features in nervous breakdowns. A man who has always taken the greatest pleasure in the society of his children will begin to snap at them without any cause. Their very presence seems to fidget him.

His companions find it out, too, for not uncommonly he begins to lose his temper when he is beaten at a game, a thing he has rarely before been known to do. But what is the clearest danger signal of all is when men or women see this irritability worming its way into the solitude of their own thoughts. In one case of neurasthenia the first sign consisted of the fact that the patient found, whenever he was alone, a tendency to have resentful and bitter thoughts even of his best friends. Once or twice he even cut his chin while shaving, simply because he was feeling so angry with a chum, who had not given him the slightest reason for animosity. Sometimes it happens that a man who has not been in the habit of swearing will find himself using bad language in the cuurse of his soliloquies. Once he starts doing that, he may know, without 
any doubt whatsoever, that his nervous system has gone wrong.

Increasing nervousness is a predominant feature of neurasthenia. It appears in various guises.

A man who has never found any

Increased difficulty in holding his own in his nervousness. dealings with others will suddenly find himself looking forward to an interview with fears and qualms. When the time comes he may be able to string himself up to the pitch, but it will only be by an effort such as he is quite unaccustomed to, and the nervous tension will perhaps leave him spent and exhausted.

Others, who have never known the meaning of the word nerves, will feel ashamed and angry with themselves when they start at the sound of a loud noise or a banging door, or are afraid to enter a dark room.

Not infrequently it happens that people who have been the first to welcome a friend in the street will commence to make a practice of crossing the road when they see anyone approaching.

Or their nervousness may take the form of a fear of the unknown. The future becomes full of dark spectres. Visions of poverty, even of the workhouse itself, will attack a man whose financial affairs are on a safe footing. A common sign of disordered nerves is a constant dread of illness. If an epidemic of influenza is prevalent, the neurasthenic will feel certain that he is to be the next victim, and his sensations, purely imaginary it may be, will confirm his forebodings. 
In whatever way neurasthenia assails anyone, it has one certain effect. It deprives them of the joy and zest of life, and when once I.oss of that has disappeared there is zest. little left. People have their different temperaments. Some are of a sanguine type, and it is no effort for them to be blithe and gay. Others are cast in a more sombre mould ; not that they are thereby miserable, for such people can enjoy themselves as much as anyone else, but in a quieter way. But when their nervous system shows signs of damage, they lose their sense of contentment just as the others lose their flow of vivacity.

All these are the premonitory signs of a breakdown, and if they are neglected the crash may come. The man finds that he cannot face his work, the woman is unable to carry out her duties in the home. Life becomes dark and void, and all that made it worth living seems to have gone.

Then too often they are assailed by the worst dread of all, the fear that they will lose their reason. For their comfort we may say that, tragic as a breakdown may be, there is a wide gulf between it and insanity.

And those who are in the preliminary stages, and have not arrived at that of a breakdown, may console themselves with the fact that the latter is one of the most preventable of conditions. It is the aim of this book to show the different ways in which it may be avoided. 


\section{CHAPTER III.}

HEALTH.

IT is surprising, in these days when everybody is an authority on matters of health, how few people there are who can tell you what it really is. The majority, if asked to describe it, would probably say that a man is healthy when he is not ill.

Now when you come to analyse this statement, it conclusively shows one thing, namely that people take illness as the standard. Health, not Most human beings, in civilised illness, the countries at any rate, have somestandard. thing the matter with them-a weak digestion, tendency to sore throats or colds, or a predisposition to ailments of one sort or another.

Yet the fact that most people suffer from illness is no reason for calling it a natural condition. It is health that is natural; illness is an anomaly. Medical men themselves are the first to recognise the truth of this statement. Animals as a rule are sound and vigorous so long as they are in a wild state. It is only when they are in captivity that they become delicate. Similarly savages are much freer from disease than civilised races. It is when they live in artificial surroundings that they become prone to sickness. 
Health is not a negative thing. It is a state in which every part is sound and acts in harmony with every other part.

The nature A motor-car consists of a great of health. number of different parts-the gear, the engine, the petrol supply, the firing. It is not sufficient that each section should be in good order. For each must also fit in, both mechanically and in point of time, with every other. The petrol pipe may be clear, but unless the spark reaches the cylinders exactly in the nick of time there will be misfiring, and a loss of power in consequence.

This loss of power is not the only harm done. It means that there will be unnecessary friction also, causing extra wear and tear to the engine and gear. If this occurs but seldom, and is put right at once when detected, little damage may be done. If repeated often, and allowed to go on uncared for, the whole structure of the car will suffer and the life of the machine be shortened.

It does not follow that the car will come to a standstill. It will continue to run, but badly. For like every other engine, it has the faculty of compensation. That is to say, when one part is out of order other parts will take on some of its work, and help, for a time at least, to make good the deficiency.

For instance, in a four-cylinder car one of the cylinders may cease to act. Yet the other three will take on a certain part of the work, and help to some extent to make up the deficiencies of the faulty one. 
This will be only for a time, however, for the additional strain will slowly but surely have a bad effect on the rest of the engine, and through it on the other parts of the machine. One by one these will give way, and have to be compensated in turn. If still neglected and left to take care of itself, there will come a time when so many sections are affected, that the remainder cannot overcome the mischief, and compensation will fail. The car will become practically useless. Perhaps, like the one-hoss shay, it will collapse en masse. It has gone beyond the stage of running badly, it has broken down.

The human system is much like a motor-car, in that it consists of a vast number of parts acting in unison. Yet it is infinitely more

The human wonderful, for it is much more machine. complicated, and can create its own supply of energy. It is made, roughly speaking, of a framework of bone and muscle, a delicately-adjusted alimentary system, whereby it takes in and assimilates food, and of a circulatory apparatus which drives blood and nourishment to all parts of the body. It contains also a nervous system, compared with which these other parts are crude, mechanical contrivances. For it is on their nervous supply that they depend for their usefulness. Cut the nerves that go to a $\operatorname{limb}$, and the finest muscles in the world are as helpless as the meat in a butcher's shop. Deprive the heart of its nerve supply for a single minute, and it will never beat again.

Yet we pay vastly more attention to a weak 
heart, as it is called, or still more so to a broken leg, than we do to a threatened failure in the nervous system, which outweighs them all in importance. Once that has got out of order, the driving power is gone. Not only the heart and muscles, but every other faculty we possess loses its energy and usefulness.

So closely allied, however, are the different parts, that the nervous system itself, which governs all else, is dependent for its welfare on the very organs it governs. Like the power of a king, it rests not only on its own intrinsic qualities, but also on the strength and harmony of the units over which it rules.

And there is a constant interplay going on between the various parts of the body. No one organ or system can stand alone.

Interplay. If it is working badly, it affects other parts, and disturbs the harmony on which the health of the whole depends.

One of the most marked examples of this is to be found in the action and reaction which take place between the digestive organs and the nervous system. The presence of congenial company at meal-times is one of the best aids to digestion; a cantankerous discussion is the very opposite. Similarly, if a man sits down to his dinner with a grievance or a worry on his mind, it is safe to predict dyspepsia.

A lady once received a telegram containing disastrous news just as she was finishing a meal. Up to that time she had never known what indigestion was, yet for the next couple of days 
she suffered from it in a most acute form. The nervous shock had thrown the stomach out of order, inhibiting the secretion of gastric juice.

-We cannot help troubles of this sort, but it is only once in a lifetime, perhaps, that we get a message of that sort during the progress of a meal. It is to be feared, however, that it is of almost daily occurrence for some people to sit down to table worrying over the business of the day. And the accumulated effects of these minor disturbances may in the long run prove more detrimental than one big one.

Conversely, the stomach has an equally potent influence over the nervous system. Everyone knows that when their digestion is out of order, and they are feeling uncomfortable or bilious, their heads are not so clear as usual. And with this there is a feeling of langour and irritability, and a difficulty in doing work efficiently. This is because the body fails to get its proper supply of nourishment, and also because it is poisoned at the same time. In order to understand the manner in which this is brought about, it is necessary to know something as to the events which are taking place throughout the body every moment of our lives.

When food is taken it is first digested and then passes out of the stomach, and is carried by means of the circulation to all

Combustion parts of the body. It nourishes and the various tissues, replacing the elimination. loss which is constantly going on. 
For there is throughout the whole system a process corresponding to combustion, and this combustion, like the furnace of an engine, is the source of our energy.

As in an ordinary fire, ashes are produced in the form of waste matter of a poisonous nature. This waste must be removed from the tissues, else it interferes with the process, as a neglected fire is apt to become choked up and burn badly.

This removal is also accomplished by the circulation. In any community you may see on any ordinary working day two sets of carts, those belonging to tradesmen which distribute groceries and vegetables, and the scavengers' carts which gather up the refuse. The same processes go on in the human body, with the difference that in this case the same agency which brings the supplies also carries away the waste.

These impurities are eliminated from the body by means of the lungs, the skin, the kidneys and bowels. And in order that this elimination may be sufficient, the circulation must be maintained in all parts of the body. Unless the blood is kept moving, this waste matter will tend to collect somewhere or other and give rise to trouble. The way in which this motion is kept up is by exercise, which squeezes out the fluid like an automatic sponge. If the body was kept perfectly still for weeks, it would became loaded with this impure material, as a room that is shut up is found to collect, in such a surprising manner, dust and dirt.

When it reaches the lungs it is purified by means 
of the air. For the air which we exhale is very different from that which is breathed in, the former being charged with impurities. The drowsy feeling which we experience in a crowded, ill-ventilated room is due entirely to the influence of these toxic gases. The purer the atmosphere we breathe, the more effective it is in carrying off impurities from the blood, so that fresh air and hygiene are essential to health, whilst exercise acts. as a valuable adjunct by increasing the respirations.

Yet exercise itself, important as it is, needs to be carried out in moderation. For the muscles, whilst fulfilling the vital functions just enumerated, produce a poison of their own, if exertion be too violent or prolonged. The severe cramp from: which athletes are liable to suffer is due to an accumulation of this toxin.

This poison is eliminated from the system during repose, and especially during sleep. Rest is therefore as requisite as exercise itself, and unless the body gets regular rest and sufficient of it, severe damage may result. The muscles will not only become permeated with their own peculiar poison, but will be so enfeebled as to be unable to assist in discharging the waste matter which is constantly being formed throughout the whole system.

These impurities are the source of many of the ills with which mankind is afflicted-headaches, vague pains in various parts, languor, and the great majority of rheumatic troubles. But their worst effect of all is that which they exert on the nervous organisation. 
For the ramifications of the nervous system penetrate to every part of the body, including the internal organs. From its seat of

Waste matter honour in the brain and spinal and the cord it sends its messages to every nervous tissue in the body, and receives system. messages in return. It may be compared to an electric power station, which distributes its current to every part of a town. But with this difference, if the electric light in a house goes wrong, it does not affect the main station, whereas if any portion of the body however small or insignificant gives way, it adversely affects the central parts of the nervous system. And if the various sections and organs do not work together smoothly, the nervous system, which governs them all, suffers along with them.

The nervous system suffers in two ways when the internate organs and other parts of the body fail to do their work properly.

First of all, it languishes frcm starvation. This does not mean that the individual is not taking sufficient quantity of food. $\mathrm{He}$

Starvation. may be taking enough, even too much, but it is not being digested or assimilated satisfactorily, and though there is plenty of food there is a deficiency of nutriment.

Secondly, it may suffer from poisoning. This may be the result of dyspepsia, for when food lies in the stomach undigested, it is

Poisoning. apt to ferment, producing a poison that circulates throughout the body. 
Or it may be because the impurities, which are found throughout the whole body, are not being got rid of, owing to a want of exercise and fresh air. Or it may be owing to undue wear and tear in consequence of a lack of sufficient rest.

Too often it is a combination of the two processes, the nervous system being attacked by starvation and poisoning at the same time.

The whole of man's structure is a marvellous automaton, and once the nervous element is disturbed the trouble which first upset the harmony is increased tenfold.

Yet the mischief may not be apparent all at once, for the whole organisation is so accurately balanced that defects in one part

Compensa- will be compensated for by other tion. organs. And whilst this is a safeguard in one way, it is a serious menace in another. For the fault is apt to be overlooked, until at last the process has gone on to such an extent that the balance is upset. The machine does not stop running, but, like a motorcar in similar circumstances, it begins to run badly. The man himself becomes what is called " run down."

It is a provision of Nature that the nervous system, being the mainspring of our existence, holds out longer than any other structure in the body. If it did not do so most of us would have been dead or broken down long ago. Yet it means that when the loss of balance reaches such a point that compensation fails, the breakdown is all the more disastrous. 
Then, when the crash comes, we blame our nerves, our civilisation, our worries and troubles, our heredity, anything in short

The cause except ourselves. Of course, there of the are cases in which circumstances breakdown. have entered over which the patient has had no control. Sometimes neurasthenia follows a severe illness or a bad accident Sometimes it comes on at critical periods of life. And in some instances heredity has played a part. There are some unfortunate individuals who have been born with weak frames and little stamina, so that even the ordinary conditions of life, however favourable, prove too much for them.

Such cases are the exception. In the great majority of instances the faults which have undermined the system are the results of mistakes, either through ignorance or thoughtlessness, in the mode of life. Not necessarily, observe, a vicious mode of life. The victims may have been consistently sober and virtuous. Yet they may have been guilty of egregious errors in regard to the quantity or quality of the food they have taken, or the way in which they have eaten it or in their neglect of fresh air, exercise or rest. The fault may lie in any one of these elements, or in more than one; in all of them, perhaps. And it is only by close examination of the habits of life that the source of the mischief

The can be brought to light. In like Remedy. manner the treatment of nervous breakdowns consists in remedying 
these faults, once they have been ascertained. Patients seldom understand this fact. What they particularly desire is a tonic to restore their jaded energies, on the principle, evidently, of whipping up a tired horse to make him go.

They look for some patent food which shall build them up in marvellous manner. Articles of this sort are valuable aids in cases where starvation from lack of sufficient food has been the cause of the trouble. But where there has been an error in diet, it has been, in an overwhelming proportion of cases, an excess of food rather than a lack of it, and when this has been so, it is about as rational to give such remedies, as it would be to pile more coals on to a fire that was already choked.

It is not sufficient merely to treat individual symptoms, taking phenacetine for headache, pepsin for indigestion, and so forth; for that is but to touch the fringe of the matter, leaving the real secret of the trouble undealt with.

Neither is it of any use to tell the sufferer that there is nothing the matter, that all he requires is to rouse himself or cease his restlessness, as the case may be. You might as well tell a drowning man who cannot swim to buck up and be cheerful.

The rest cure, so much in vogue, may have its advantages in some cases, but too frequently the patient leaves the institution only to resume his former mode of life, and repeat the very mistakes which brought on the illness. A consumptive might as well never enter a sanatorium if he is to return to a badly-ventilated house and unwholesome surroundings. 
Not uncommonly it happens that a man will make up his mind to have a course of treatment at some spa, even though it means a sacrifice of time and money. When he is told that it is his manner of life that needs overhauling, the commonplaceness of the observation affronts him. Like Naaman, he expects to be sent, if not to the waters of Jordan, at any rate to those of Homburg or some such resort, and he strongly objects to being told that all he needs he can get at home.

Some time ago I was travelling from London to Buxton. There were two other men in the carriage, and one of them was telling the other that he was going there for his health. He said that he found it necessary to go several times a year, as he got so run down. The other man asked him what treatment he had on these occasions, did he have baths or drink the waters or what?

"No," answered the first one, "I simply get up early and go to bed in good time and take plain food."

"And why don't you do it at home instead ?" inquired the other.

There was no reply. 


\section{CHAPTER IV.}

THE VALUE OF HEALTH.

THE supreme value of good health is the fact that it is associated with happiness and a greater capacity for good work.

It is not our environment but our state of health which handicaps us. Mark Tapley succeeded in ejaculating "jolly"

Health under the most depressing circumand stances. I know nothing as to

happiness. Mark's medical history, but I should not hesitate to affirm that he did not suffer from a disordered liver.

Everything in this world varies according to the way it is looked at, and we are all liable to develop mental astigmatism when we are not feeling up to the mark. A man will say and do things that are foreign to his nature when he is waiting in impatient hunger for his dinner. Wives who are wise have found this out, and wait until the brute has been fed before they broach the subject of a new hat.

A man who has nothing special to worry him, and who if any difficult position arose would face it without flinching, will brood over his affairs during the hours of a sleepless night until he has created troubles enough to last him for the rest of his life. His business may be running like 
clockwork, but before morning he will have convinced himself that he is on the road to the workhouse. A good night's rest, a brisk walk, even a cup of tea will work wonders in a careworn man or woman, who has almost come to the conclusion that life was not worth living.

One of the most prominent symptoms of jaundice is the depression which accompanies that malady. There is a solid substratum of truth in the old saying, "Looking at the world through jaundiced eyes."

The most trying part of nursing sick people is the cantankerousness which. even the besttempered persons tend to develop when they are ill or in pain. The most considerate of patients are apt to become positively unreasonable at such times. Yet because of their sufferings they nced all the sympathy and patience that can be bestowed upon them. And as a rule, so long as they are really ill and laid aside, they get it. What the world gets sick of is the croaker, who never ceases talking about his ailments. People may sympathise with him for a time, but before long they get tired of hearing about his complaints. It is only human nature to prefer listening to skylarks rather than to frogs.

Perhaps the most serious effect of ill-health is the loss of confidence which it entails. Many a man of frail physique and little Health stamina has been left behind by and work. others not nearly so richly endowed with skill or intellectual ability. He has the accomplishments, but not the power 
to use them. He is so afraid of making mistakes, that the psychological moment has gone past before he has made up his mind, and time after time he fails to take the tide at the flood.

Trace back the history of characters such as this, and you will find that in almost all cases thoy have been weakly boys, who on account of their lack of vigour and health were always afraid to take the plunge. They might learn to swim, but they could not learn to dive.

A rising young Member of Parliament was once asked what quality was most indispensable for success in the House of Commons? Some expected him to say the art of speaking, others the faculty of rapid thinking, others again firmness of convictions. All were surprised when he replied, "Good bodily health. That," he said, "was more important than anything else."

When you come to analyse that statement, it is found to imply more than the strength to endure the enervating atmosphere of the House or the tedium of long sittings. It means that if a man is well and strong he is able to seize every opportunity of speaking, or otherwise showing his capabilities and making use of them. Good health is not merely a valuable asset in itself, it unlocks the door of all the other faculties.

Most of us are not going into Parliament, but most of vis have to make our living. And no matter in what way we have to do it, whether by artisanship, business or professional career, vigour and robustness are essential to success.

An employer when about to engage a hand will 
most certainly give the preference to a candidate who looks strong and seems in good spirits. And this for more than mere consideration as to workmen's compensation. For we have all learned to associate cheerfulness with ability. If a man undertakes a job as if he enjoys it, even if it is only a plumber mending a kitchen sink, we naturally conclude that he knows what he is about. If on the other hand he looks worried, we suspect that he has come across difficulties- that he does not understand. If he seems to have no confidence in himself, we cease to have any confidence in him.

We are all more inclined to extend our patronage to a tradesman who serves with a beaming smile than to one who looks as if he would be thankful to see the last of us.

And in any avocation good health goes a long way by contributing that quiet contentment of mind which is a sine qua non to the attainment of excellence.

It is a dictum in the medical profession that you can always tell the state of a surgeon's digestion by the amount of confidence with which he makes his incisions.

The parson who enters the pulpit with an air of robust vigour is vastly better calculated to secure the attention of his hearers than one who crawls in looking as if he wished it were all over.

A man who is at the head of a large business awoke one morning feeling out of sorts. His breakfast disagreed with him, and he arrived at 
his destination in a state of irritability. Then he rapped out at his subordinates until he had flurried them to such an extent that they could not do their work properly. And of course after that everything else went wrong. When he was called on to come to a decision in regard to an important contract, he got the worst of the bargain simply through lack of a little tact. Yet ordinarily he was noted for powers of dealing, and for a judgment that was rarely at fault. That day he was the victim of his own stomach.

Want of stamina has deprived the world of some who might have done much to ease its woes and help its advancement. For it effectually limits the sphere of a man's operations. There are some of conspicuous ability who have had to waste their talents in some quiet backwater, when had they but had the requisite amount of strength they might have occupied a prominent place in public affairs. Young men who have possessed every other fitting quality have been rejected for the missionary cause because their health was not good enough to stand the hardships of such a life.

Some may ask as to whether good work has not been done by those crippled by ill-health. Undoubtedly it has been done, yet as a rule it has been by those endowed with talents which enabled them to carry out their work in seclusion -writers, poets, composers and so forth-not by those compelled to take their place among the rank and file in the busy world of men and things. Too often : in the latter case they have fallen behind 
and been submerged. Even if success has been their lot, it has been at such a cost to mind and body alike as to make it scarcely worth the while.

Yet even those who have been in the fortunate position of being able to exercise their talents in solitude, far from the madding crowd, have betrayed the influence of their infirmities in the nature of their works. Schubert and Chopin both wrote exquisite music, yet their weak state of health still reveals itself in the melancholy strain which pervades their compositions. The same is characteristic of some of the writers and poets. Robert Louis Stevenson is the great exception. But the disease which attacked him in his young days, and dogged his steps mercilessly to the end of his life, was one that is oftentimes, strangely enough, characterised by buoyancy and enthusiasm, in marked contrast to the prevailing depression of the confirmed dyspeptic, of which Carlyle was such a marked example. Yet what chicfly enabled Stevenson to keep up the vigour and inimitable style of his writing to the day of his death was the unremitting care which he took in order to regulate his life in such a way as to preserve his energies and ketp his mental powers intact to the very end. That last broken sentence, the most pathetic ever written, in Weir of Hermiston, is more than an expression of his great genius; it is a lasting tribute to the vigilance with which he safeguarded such strength as he possessed. It is a lasting reproach to those who have been gifted with robust health, and by their 
own heedlessness have lost what is man's most priceless possession. People may disregard the laws of health and appear for a time to go unscathed. But the day of retribution will come, and outraged Nature assert itself. Sooner or later the inevitable penalty must be paid. 


\section{CHAPTER V.}

REWARDS AND PENALTIES.

SOME people expect health, as others expect riches, to fall into their lap. Either because they do not know, or do not care,

The health- they prefer to leave their health seeker. to look after itself. They call it trusting to Nature. And when they see other people studying the best way to be strong and well, they call them cranks and faddists.

There is a vast difference, however, between the faddist and the genuine health-seeker. The individual who thinks the world is going to be saved by eating brown bread or any other article of diet, regardless of the fact that what agrees with one may upset another, is nothing short of a nuisance. The man who strives to exercise his common sense, and to find out what suits him, either from his own experience or from the advice of those in a position to give him useful information, is worthy of all respect.

It is all very well to talk of leaving things to Nature, but does Nature always do her work in the best possible way?

Leave a garden to Nature for a year, and you will have a clear answer to that question. It will be overgrown with weeds. Leave a tract of country to Nature, and it becomes a wilderness. 
Leave your health to Nature, and it will be nothing short of a miracle if she does not make a mess of it.

Talk to any elderly man, who has succeeded in keeping himself fit and strong, and almost certainly you will find that he has well-defined ideas on the maintenance of health. $\mathrm{He}$ has found out what agrees with him and what does not. Sometimes he appears to be careless as to what he eats, taking things that would disagree with many other persons. Yet he is only taking them because he has discovered that they suit his constitution. Moreover, you will notice, if you watch him closely, that he is extremely particular as to the way in which he eats that food and all his other food as well. A man is either a physician or a fool at forty, it is said. The worst of it is that by the time most of us have reached that age we have managed to inflict more harm than can be undone.

Nowadays nearly everything is taught in the schools, including perhaps a few subjects that might well be spared. When the teaching of health is made compulsory, we shall make rapid strides in regard to national physique. The medical inspection of schools was one of the greatest advances ever made. And when in addition every child is instructed in the elementary rules of health, the country will be spared a vast amount of time and money, such as is expended at present in looking after the feeble and diseased. We do not expect a boy or girl to learn any other subject on its own account or of its own freewill, and we have no right to expect them to learn the 
secrets of health. They must be taught them just as they are taught to read and write. Above all, they must have it impressed upon them that health is largely a matter of care and study.

The reason why some people are stronger than others is, in the great majority of cases, because they have taken care of them-

The reward selves, rather than because they of care. have inherited more robust frames and greater staying powers. There are some, it is true, who have to struggle against ill-health from their earliest childhood. All through life, it may be, they have to contend against their own infirmities.

Yet not uncommonly it has turned out that those who have been handicapped from the start have in the long run passed their more robust comrades. It is not always the healthy baby that develops into the hardiest member of the family. The puny little one has been known to have the best of it in regard to health by the time it has grown up.

And when this happens it is simply a reward for taking care. Parents are bound to pay more attention to a weakly child, while the robust ones are often left to take their chance, and as they grow up into boyhood and manhood, the delicate one has still to exercise care and look after his health, if only for his own comfort. He knows, even in his schooldays, that if he eats too much pastry or sweets, or neglects to change his clothes if he gets a wetting, he will have to suffer for it. All this time his hardy brother is running all sorts 
of risks, and playing ducks and drakes with his digestion and his constitution in general.

When they are approaching middle age, the strong one has developed into a gouty, dyspeptic individual, who does not know what it is to feel. well for a single week at a time. And the weakly one may be better and stronger than he has ever been in his life before.

He has never been able to do anything by leaps and bounds, but he has plodded steadily on, exercising care and common sense, and looking after his health in every possible way. It is. another example of the hare and the tortoise.

Two men were crossing a ship's gangway, which had a rail at one side but was unprotected on the other. The first was a frail, nervous man, while his friend who followed him was a strong, lusty fellow. The delicate one took care to keep a firm. grip on the rail. He reached the ship's side in safety. The second man disdained to avail himself of its aid, and walked up the gangway with his hands in his pockets, paying no heed to his steps. Suddenly he lost his balance and fell into. the water.

He scrambled out and cursed his bad luck. "He was the most unfortunate beggar that ever lived," he said. He completely lost sight of the fact that it was his own carelessness which had brought about the mishap.

And it is a common occurrence to hear people, who have been running all sorts of unnecessary risks, complaining of their bad fortune when illness overtakes them. They get wet through 
and sit in their damp clothes, and are very much aggrieved when they take a chill. Or they gorge themselves with pastry or sweetmeats, and consider themselves martyrs when they suffer from a bilious attack.

There is one penalty ever before us, that which must be paid by all who transgress the laws of health. I say penalty, not punish-

The inevit- ment. A boy who has purloined a able penalty. plum cake and eaten inordinately of it may obtain his mother's forgiveness, but the chances are that he will be penalised by having to endure a bout of stomachache.

In all this I have no wish to imply that those who disregard the laws of health do so from self-indulgence. On the contrary, the great majority of breakdowns occur in those who have overtaxed their strength whilst toiling to support their wives and tamilies, or to minister to the welfare or comfort of those around them, or to labour in some way or other on behalf of humanity.

In a Midland town two young parsons worked side by side. One of them was a genial sort of fellow, who seemed to have plenty of time for everything, work and play alike. When his labours were over for the day, people enjoyed having him in for a bit of supper and a chat.

On bright days, Mondays particularly, he would mount his bicycle or shoulder his golf clubs, and set off to have a good time of it. His doings were a puzzle to his confrère, who never had a 
minute to spare, and rushed at his work, sermonmaking, visiting, and meetings alike, with feverish anxiety. Even his meals were hurried through in the same manner, for those, like recreation, he regarded as an interference with his duties.

When his daily work came to an end, he would proceed to make up for lost time by reading or writing till long after midnight, with the result that such sleep as he got when he went to bed was simply the broken sleep of brain exhaustion.

Little wonder that he always looked strained and anxious, and that when he went into the pulpit on Sundays he failed to get into touch with his hearers. With all his unceasing efforts, he could not but realise that his friend had a vastly greater hold on the people than he was ever able to acquire. Then he would conclude that it must be due to some fault in himself, and would begin to look for it in the wrong place, viz. in his own soul. It must be some black place in his own heart, he thought, which was hindering his work.

Now when a man indulges in too much introspection he is very liable to develop a morbid conscience, and see evil in himself that is purely imaginary. Hypochondriacs of any sort are a nuisance both to themselves and other people, but none more so than the spiritual hypochondriac. The consequence of these heartsearchings was that he would increase his efforts, and try to squeeze more work into the day.

He was sitting at breakfast one day scanning the morning paper, when a head-line attracted 
his notice, "Death of the Rev. X. Y." The paragraph described how X. Y., whom the young parson had always taken as his model for energy and unremitting toil, had had to relinquish his duties owing to a nervous breakdown, brought on by overwork and the lack of holidays or recreation of any sort.

The young man's eyes dilated with horror as he went on reading and realised the unmistakable fact that X. Y. had brought about his own death. The thought that such a fate might one day be his own sent a shudder through him, especially when it dawned upon him that he had been doing his work on precisely the same lines as those which had culminated in this tragedy.

It is not often that a man is so fortunate as to have such an object-lesson as this. More frequently he is allowed to persist in ways which lead, if not to a disaster like the one referred to, at any rate to a breakdown, which puts a stop to his career of usefulness.

No matter how lofty may be the motives, Nature takes no account of them. She is a jealous mistress, and insists on No account having her due share of attention, of motives. allowing of no excuses. The mother who neglects her own needs through attending to the wants of her children will suffer equally with the silly girl who starves herself in order to keep her figure slim.

If a man stands out in the driving rain, he is equally susceptible to cold, whether he stood there in order to watch a football match or to take 
part in an evangelistic meeting. It is as injurious to sit in a draught in a church as in a music-hall. A stuffy atmosphere is no less detrimental to health whether we encounter it whilst visiting a sick friend or in spending the time in a gambling den.

Two of the worst cases of breakdown which I ever heard of occurred respectively in the case of a working man, who had starved himself in the necessaries of life in order to bring up three orphan nephews and nieces, and in that of a young professional man, who sat up every night for weeks, after doing his work by day, to nurse his wife through a dangerous illness.

There are hundreds of people drifting towards a breakdown, not because of their circumstances or the nature of their avocation, Health lies but because of the way in which in our own they choose to live and do their hands. work. Health is a matter that lies in our own hands to a far greater extent than is usually supposed. All who wish to fulfil their mission in life to the best of their ability, and maintain their power of work as long as possible, must keep one eye on their work and the other on their health. Whilst doing their duty to others, they must not fail to do justice to themselves.

I once saw two men playing golf, both of whom were men of fame. One was a writer of repute, the other an orator whose name is known far and wide. They played round with an abandon and zest that was refreshing to witness. But what 
impressed me most was a remark made by one of them when they came in.

"My friend and I were anxious to get a game to-day," he said, " because we are the principal speakers at two mass meetings to-night, and the people are expecting something special, so we must be prepared to let them have it."

That was why, instead of immersing themselves in studious solitude, rehearsing their speeches, they spent the time in playing a game like a couple of schoolboys out for a holiday, with a good tea and a rest to follow. It is a dozen years since that happened, but those two men, who are among the hardest public workers of the day, are as fresh and fit for their duties now as they were then. And this, not from any natural strength or stamina, but simply because they have always taken pains to carry out the fundamental laws of health.

The remainder of this book will be directed to the consideration of these laws, on which the whole question of breakdowns and their prevention depends. 


\section{CHAPTER VI.}

THE HUMAN ENGINE AND HOW TO STOKE IT.

AN express train was standing in a London terminus, on the point of starting for her run to Edinburgh. Several persons were admiring the great locomotive, which was throbbing like a hound in leash, ready to be off the moment the guard's signal was given. The guard waved his flag, and the train glided out of the station so smoothly, that the unwary passenger standing up in his compartment at the time was not even jolted. The first stopping-place, a hundred miles away, was reached on the stroke of time, without a hitch of any sort.

The man who was responsible for this perfect running was not the driver so much as the stoker, that humble individual, as we are apt to regard him, whose duty it was to put the coal on the fires. Unless he had done his work efficiently, the best driver of the finest locomotive ever built could not have made a good run.

He took care to use the right sort of coal, to put in enough of it to keep the fires bright, but not so much as to choke them up, and to shovel it in with discretion and at suitable times. Few people realise that there is a distinct art in stoking a furnace.

Yet that stoker was not a happy man. He was 
sallow and of a livery type. He often suffered from headaches and spots before his eyes, heartburn and nausea. Although he was muscular and powerfully built, he frequently felt so tired and listless that he was hardly able to face his day's work.

All this was due to the circumstance that, although he had mastered the stoking of an engine, he had never learned to feed himself properly. He had not realised that he himself was an engine, quite as much so as the locomotive he worked on, and that the food he took was the fuel which supplied the driving power to his system and kept his machinery running. It had never dawned on him that there is an art in eating just as important as that of stoking, and demanding as much care and foresight.

$\mathrm{He}$ would take his meals at any time that happened to be convenient, and would eat anything that came before him, regardless as to whether it suited him or not. Furthermore, he often ate to repletion, and bolted his food down without masticating it properly. And that was why his own machinery ran badly and he felt tired and depressed. In which respects he was exactly like thousands of other people.

This resemblance between a steam engine and the human body is a pronounced one. As we have already pointed out, the food, after being digested and absorbed through the walls of the digestive tract, is burnt up in the tissues by a process closely corresponding to that of ordinary combustion, and there is a residue of waste 
products left behind resembling the cinders and ashes of a coal fire. Nature is able in various ways to dispose of this waste, eliminating it from the body. If, however, the amount of food taken be excessive, the residue is so large that the resources of the system are not sufficient to cope with it, and in consequence it accumulates in the tissues.

Then the individual suffers from discomfort or pains in the muscles, and from headache with a sense of tiredness, even apart from exercise or work; also from various other symptoms, owing to this waste matter circulating in the blood.

The wrong sort of food may have been taken, or eaten either too quickly or at unsuitable times, and dyspepsia results. Then there is a certain amount of undigested food constantly left behind in the stomach, and this begins to ferment, developing a poison of its own, which gets into the circulation and aggravates the effect of that already present. At the same time the nutritive quality of the food is diminished, so that there is superadded a process of starvation. There is plenty of food, but little nourishment.

The final stage is therefore one of poisoning and inanition combined. The effect of this on the whole body, and especially on the nervous system, is harmful to the last degree. The headaches are accentuated, and the individual feels depressed and irritable. The irritating influence of these baneful products is so marked, that the different organs begin to show signs of the damage which is slowly but surely taking place, and the delicate 
nervous system feels the influence of it most of all. The pain, discomfort and nausea caused by the contact of acid undigested food with the lining of the stomach add to the feeling of misery.

This may go on for years, until with one thing and another life is hardly worth living. It may disappear for a time, only to return, perhaps, in an aggravated form. Meanwhile the strain on the whole organisation becomes greater, as the organs grow less capable of propping each other up. If it is allowed to continue indefinitely, the time may come when Nature will rebel, refusing to be treated in this scurvy manner any longer.

The art of feeding resolves itself into four considerations: the sort of food to take, the amount necessary, how and when to eat it. 


\title{
CHAPTER VII.
}

\author{
WHAT TO EAT.
}

Simple as this may appear at first sight, it is one of the most difficult problems with which human beings are confronted. The diet of a horse is limited, so is that of fowls. Among wild animals we find some that are flesh eaters, such as the lion and the tiger, while others live on vegetables or fruits. Man, on the other hand, like the pig (save the mark!) eats everything, and the question is what to choose out of this unlimited bill of fare.

We must remember that people are not all built alike, and that what is one man's food is another's poison. There is no greater

Differences mistake than that of imitating of other people. The native of India constitutions. thrives on rice, but white men who attempt to live exclusively on it soon find their systems going to pieces.

Even among persons of the same race we find marked differences. One of our neighbours flourishes on vegetables and bread; we adopt the same diet, with the result that we become too tired to do our work. Another takes meat three times a day and looks well on it; we try the same, and grow gouty. Another consumes a quart of 
milk a day in addition to his ordinary food, and says he cannot get on without it; we follow his example, and get a bilious attack.

There is a hale old gentleman of eighty who takes every night a supper of bread and cheese, with beer and walnuts to follow, going to bed immediately afterwards, and waking up fresh and vigorous in the morning. Most of us, if we took a supper like that, would go to bed to stay there.

The fact is that there is no general rule applicable to everyone. Some people thrive on a vegetarian diet, but others cannot get along on it at all ; and the same remark applies to every other such restriction. It rests with each individual to discover for himself or herself what foods suit them best and keep to them, avoiding any which manifestly disagree.

Within reasonable bounds the question of likes and dislikes is a useful guide. Rich, highlyseasoned dishes are of course bad

Likes and for everybody; but as applied to dislikes. plain, healthy articles of food, it is safe to say that what people like agrees with them, and vice versa.

As to dislikes, there are no two opinions on the subject. If the taste of any food is repugnant it should be avoided like poison. In fact, so far as that particular person is concerned, it probably is a poison. Some people dislike cheese to such an extent that they cannot even swallow it, try as they may. If they did succeed in getting it down the results would most likely be disastrous. I know of one family who cannot take eggs in any 
form, not even in the smallest quantity as a mere flavouring. If they get it by mistake they are ill with an attack resembling acute gastritis for days afterwards.

It does not follow that a patient has been living luxuriously because he is suffering from habitual dyspepsia. It is not uncommon to hear people say that they cannot understand why they should be so afflicted, as their diet had been of the plainest. Bacon and dry bread, with toast and marmalade to follow, sounds rational enough in all conscience. But if the bacon is badly fried and swimming in fat, the bread new, and the toast hot and soaked in butter, it is not surprising that people feel wretched and uncomfortable for the rest of the morning.

The way in which food is cooked has always to be taken into consideration. Some cooks and housewives have a, genius for spoiling good food, either in the way they prepare it or by their neglect to clean the pots and pans. Greasy saucepans have much to account for.

Sometimes, however, the fault lies at the door of the person concerned. A partiality for new bread, and an unwillingness to give

Classes of it up when so advised, have been at food. the root of a chronic dyspepsia with all its attendant evils. Articles of diet are divided into four classes : Proteids or meat foods, carbohydrates or starchy, oils and fats, water and other liquids.

Proteids or meat foods, include fish, fowl, butcher's meat, and vegetables, such as peas, 
beans and lentils. The problem of Meats. meat, and particularly butcher's meat, is a vital one for all who are getting on in years. So long as people have no organic disease necessitating special diet they cannot go far wrong in regard to fowl, fish, tongue, ham or bacon. It is a different matter when we come to deal with butcher's meat, for this contains a large proportion of fibre, which constitutes one of the most difficult forms of waste matter to get rid of.

And the ill-effects of this waste matter are more pronounced as people get older, for however healthy they may be, their systems

Meat and become less capable of eliminating gout. it. It is an excellent rule, therefore, for all persons approaching middle age, even for those who have got into the forties, to reduce their allowance of butcher's meat, especially beef, taking it no oftener than once a day, and preferably at midday instead of in the evening. Digestion goes on very slowly, if at all, during the hours of sleep, and the habit of eating meat at late dinner or supper is one of the chief causes tending to gout and rheumatism of the gouty type.

It is this disease in some phase or other which is the starting-point of so many breakdowns in health. The harmful residue in the system affects almost every organ and tissue, and the arteries in particular. Its most serious effect is on the vessels of the kidney: when once they have become thickened, the elimination of waste 
matter is reduced to dangerous limits. Then the health of the whole system is imperilled, for one of the most important outlets has become blocked up.

Too often this complication means the beginning of the end, the onset of premature old age. It is on this account, and not from any desire to advocate vegetarianism, that $I$ have emphasised the necessity of diminishing the quantity of butcher's meat, once the period of early manhood has gone past. It fact, it would be to the benefit of all, young and old alike, to take nothing heavier than fish or fowl at least one or two days a week.

Carbohydrates or starchy foods. These include bread, sago, tapioca, rice, and underground vegetables such as potatoes. Bread Starchy is the most important of these. It foods. is called the staff of life, and yet it accounts for more dyspepsia than all other causes put together, and for more miserableness than all the incidental troubles and misfortunes of life in one. For there is nothing which depresses a man's spirits so effectually as dyspepsia, and an overwhelming proportion of cases of this complaint are due to the imperfect digestion of starchy foods, of which bread is the most common.

Starchy foods are dealt with by the saliva, and this, in order to do its work properly, must penetrate to the heart of the The granules. And this it cannot do if saliva. something else has got there first. People are often surprised when 
they get indigestion after partaking of bread and milk; that is, bread soaked in hot milk. But the milk has permeated the starch granules, and as two things cannot be in the same place at the same time, the saliva cannot get there.

This explains why bread is the source of so much discomfort. For bread, as it is usually made in this country, is more or less moist, and consequently the saliva has the same difficulty to encounter as in the case of bread and milk. The water has arrived first and keeps the saliva out. If the process were carried on to a further and drier stage, as in the hardbake of the Colonial, we should be able to assimilate it with ease.

We are apt to envy the Oriental his capacity for digesting starch. Yet his powers in this direction are due not so much to any inherited faculty on his part as to the way in which the rice is cooked. The glutinous material on the outside of the granules prevents the saliva from penetrating. The Oriental gets rid of it by washing the rice in cold water half-way through the cooking, rubbing it between his hands at the same time. The writer once recommended this plan to a lady who complained of indigestion after eating rice, and told her that if she insisted on its being carried out she would have no further difficulty in the matter. She replied that there would be a great difficulty-the cook would immediately give notice.

Yet if these hints as to the preparation of starchy foods were taken advantage of, we should 
hear much less of the fermentative

The slow dyspepsia which is at the root of poison of so much of the slow poisoning from dyspepsia. which many people suffer, to the detriment of their general health and their nervous systems in particular.

It is this slow, long-continued poisoning which undermines the nervous system and lays it open to attack from all the other causes that predispose to a breakdown. No amount of inconvenience or self-denial is too great that can lead to the avoidance of the dyspepsia which causes it. And this ailment may accompany the plainest and simplest of diets, if they are taken in the wrong way. Space would not permit of our treating this fully, but mention will be made of two or three common articles of diet which are liable to be followed by indigestion.

Apart from any special idiosyncrasy, many people suffer from nausea or some other form of discomfort after taking eggs. It is

Eggs. not uncommon to hear people say that they can take them in the latter part of the day, but not in the mornings, without some ill-effect. If that is so, they should be careful to avoid having them for breakfast, for when taken at this meal they are often responsible for headaches which come on in the course of the morning.

In many cases these bad effects can be avoided by having the eggs boiled for eight minutes. This prolonged boiling reduces the contents to a light powder, and seems to get rid of some element that is of a poisonous nature. 
A small quantity of soup is beneficial as a preliminary to dinner. If a man is tired after his day's work it stimulates the Soup. digestion and puts it into a better condition to do its work. On the other hand, it is a great mistake to take too much of it, as then it is apt to swamp the stomach with so much liquid as to hinder the secretion of gastric juice.

Some people can digest fat who cannot take oil without becoming bilious, and some cannot take either. Yet it is as a rule the very

Fats and ones who cannot take one or the oils. other who try to do so, in spite of their aversion for it. It seems strange that it is stout people who are best able to digest fat, and thin ones who cannot do so. It is not so strange after all, however, for the simple reason that people are thin because they cannot assimilate fat.

Yet oftentimes we find such persons persevering in taking fat or even cod-liver oil, in order to put on flesh. The result is, in many instances, that they become thinner than ever, owing to their digestions being thrown completely out of order.

Milk is the ideal food. Yet there is no food, however ideal, which can be regarded as universal. There are some people, and not a Milk. few, who cannot take milk without suffering from indigestion or biliousness. Even among children one finds this peculiarity at times; if such youngsters are forced to drink it, they are upset in consequence. 
This is often due to the fact that it is taken raw and undiluted. There is a widely-prevalent theory to the effect that any interference with the milk in its natural state deprives it of its nutritive qualities. This is not the case. If the milk is boiled, for instance, a certain substance which it contains, casein by name, undergoes a change. Yet it is this casein which causes the curdling of milk that is prone to take place in many stomachs, producing flatulence, pain, and it may be actual vomiting. This casein is nutritious to those whose digestions can cope with it, but for those who cannot digest it the boiling is of great advantage, as the remaining elements of the milk become more nutritious because more digestible.

It is of no use simply to heat the milk, it must be actually brought to the boil. -If the taste of it in this form is objected to, this can be overcome by adding a little sugar or salt, or a flavouring of nutmeg. And if the patients do not care for it hot, it may be cooled down and taken cold with or without soda-water.

Sour milk, either in the form of ordinary butter-milk or prepared in the scientific manner, is one of the healthiest of drinks. It has been a well-established fact for many years that people living in parts of the country where the drinking of butter-milk is in vogue are exceptionally healthy. This led to the researches which culminated in the sour milk treatment, which came so much to the front a few years ago. It was a valuable discovery, for many of us are so situated that we cannot get butter-milk. 
Also, the scientific way of preparing it is much cleaner and more satisfactory than the old crude one, which was liable to implant other and less desirable germs in our inside along with the health-giving ones.

When this treatment came into vogue we were all to lose our aches and pains, and enjoy robust health or something approaching it. Already, in this short time, the method has fallen almost into disrepute. And simply, so people said, because it did not do what. it professed. In this they did it a great injustice. If it did not do what it professed to accomplish it was only because it did not have a chance. If people continue to eat all sorts of unsuitable things and bolt them down, they need not expect to whitewash their insides by taking sour milk on the top of an injudicious diet. Like a good many other adjuncts to health, it has to be taken with a grain, not of salt but of sound common sense.

People are often perplexed on the question of sauces, as to whether they are harmful or otherwise, A rich, oily sauce is only Sauces. too likely to cause dyspepsia, but a flavouring of what we might term a "clean" sauce is often an aid to digestion. For in spite of all that has been said and written on the subject of plain foods, there is no doubt that if a taste is pleasant it tends to stimulate the flow of saliva and gastric juice. There is a scientific foundation for the saying, "It makes my mouth water."

The main disadvantages of sauces and spices 
is that if used to excess they are apt to increase the appetite more than they stimulate the gastric juice, and so lead to more food being taken than can be digested.

After all, hunger is the best sauce, and the man who has earned his meal by work or exercise has little need of artificial aids and flavourings.

A vast amount of evil has been attributed to the use of tea. To a certain extent this condemnation is true. Yet it is

Tea. not so much the tea itself as the way in which it is made and the conditions under which it is taken that are to be blamed for the mischief.

If allowed to stand stewing for long it is nothing short of a poison. For then it is converted into a concentrated extract of tannin, which has a most irritating effect on the wall of the stomach, producing a secretion of acid liquid, causing heartburn and perhaps injuring the delicate mucous membrane to the point of ulceration.

There is also another deleterious substance present called thein, and this has a specially pernicious influence on the nervous system when taken in excess. If tea is drunk within a few minutes of being made there is just enough of this alkaloid to produce a pleasant, refreshing effect without any harm being done. Yet even when prepared in this way, but taken too frequently, the accumulated effect of repeated small doses is as injurious as a large one, causing nervous irritability and sleeplessness.

In many instances the harm of tea-drinking lies 
in the fact of its being taken at wrong times. The custom of drinking it after a meal such as dinner is a bad one, as it retards the flow of gastric juice.

Of all pernicious customs there is none more to be deprecated than that of high tea, as it is called. It is a sociable meal, but a deadly one. Many of us look back with a shudder to an array of sardines, tongue, ham or fish, followed by bread and butter with two sorts of jam, buns and cakes of all sorts, washed down with copious draughts of strong tea

The use of tea, as opposed to its abuse or misuse, is highly beneficial to the system. There is no remedy equal to it for a tired headache. It washes out the stomach and gives it a fresh start for the next meal. A cup of tea in the early morning will often enable a better breakfast to be taken, and one in the afternoon between four and five o'clock helps to complete the digestion of the midday meal.

Furthermore, it serves a good purpose in making the blood circulate more freely and in dilating the vessels of the skin, thus assisting in the elimination of waste matter. In this respect it is much better adapted than cold drinks in hot weather, particularly for those engaged in active outdoor games, such as tennis:' For it makes a more efficient thirst-quencher, and by flushing out the tissues helps to prevent the onset of fatigue.

Have it freshly made, take it in moderation, and it will never do any harm. Especially is this the case with China tea, if taken in preference to 
Indian, for it does not injure the stomach or the nerves in the way that the latter is apt to do.

Coffee does not as a rule tend to cause indigestion or affect the nerves; its ill-effects are due to the fact of its causing biliousness. Coffee. People of what is known as a "livery" type had better avoid it altogether, if they have found it to have this result. Yet they might as well ascertain first as to whether it was the coffee or the milk which they took with it which accounted for their discomfort. It is a mystery as to why people, who cannot on their own assertion take hot milk without upsetting their livers, should drink it when its taste is disguised by that of coffee. The milk is there just the same, and the after-effects are bound to be as bad as if taken by itself.

Let such persons take their coffee thin, making it with water, and adding only as much milk as they would put into their tea, and it will probably turn out that they can take it without any bad after-effects.

There is one form, however, in which this beverage is harmful. That is in the form of black coffee. When taken in this form it certainly causes indigestion as well as biliousness. Some of the most persistent causes of dyspepsia, especially that which is most pronounced on waking up in the morning, are due entirely to the habit of drinking black coffee after dinner in the evenings. And the taste is evidently a seductive one, for there is no habit, not even that of alcohol, more difficult to eradicate. Yet until 
the use of coffee in this form is given up, the dyspepsia will most surely persist.

The amount of liquid consumed in the twentyfour hours is one of the most important questions in connection with diet, especially Water. for anyone suffering from headaches, rheumatic pains, malaise, undue fatigue, and a variety of suchlike complaints, "minor ailments" as they are called. These ailments are anything but minor, we may observe, in regard to the amount of suffering they cause, and the train of symptoms and diseases to which they lead.

Without a sufficient quantity of liquids the waste matter in the tissues is apt to become too. condensed, and on this account less able to reach the eliminatory organs, whose function it is to throw it off. It not uncommon'y happens that a man will consult a doctor, complaining that he is suffering from pains in his limbs, either in the muscles or the joints or both, also from a constant dull headache and sense of tiredness. He fears that he is on the verge of rheumatic fever, and it is not improbable that that is exactly what he is. On inquiry it turns out that he has been in the habit of taking very little liquid either with meals or between them. He is told to take an extra quart, two if possible, a day. Then it often happens that in a week or two all his symptoms have disappeared, and he is capable of as much exertion as he ever was.

The liquid may be taken in any form, hot or cold, or in tea, coffee, lemon water or any other 
beverage the person may prefer. It does not matter how it is taken, so long as it gets into the system.

So much has been written and spoken on the subject of alcohol, that it would seem almost unnecessary to discuss it fully here.

Alcohol. Ten or fifteen years ago the necessity would have been vastly more pressing than it is to-day. For no change is more remarkable than that which has come over public opinion on this topic of recent years. For nearly a century temperance reformers have been combating the moral effect of strong drink. Then the medical aspect of the question came to the fore, and the moderate drinker began to wonder if the matter did not apply to himself as well as to the drunkard.

Excess is a matter of personal equation, and many men who have always considered themselves strictly temperate have begun to realise that while the amount they were taking was not sufficient to affect their moral fibre, it was too much so far as their bodily health was concerned. Consequently a welcome improvement has been manifest in the drinking habits of the community. The growth of athletics has no doubt had much to do with this change.

It may be, too, that the attitude of the medical profession has had a share. Twenty or thirty years ago it was a dangerous thing for a doctor to tell a patient to reduce his ration of alcohol. Now the profession gives its orders on the point with as little hesitation as it exhibits in ordering 
a diet. And the public has shown its appreciation of this fact in the view it has taken. Once a doctor who did not order wine during convalescence was looked upon as a faddist. Now he is regarded as old-fashioned if he does so, unless there is some special reason for it.

While reserving for every man the right of his own opinions as to alcohol as a beverage, medical men rarely order it save as a drug, as in the administration of brandy in acute illness

Perhaps the most significant proof of the change in public opinion is the fact that many patients now ask a doctor, not which form of alcohol is " the best for them," but which " will do them the least harm." 


\section{CHAPTER VIII.}

\section{HOW TO EAT FOOD.}

THIS is even more important than the nature of the food itself. The great majority of digestive troubles are due to the habit of

Mastication. taking food too quickly, and imperfectly masticating it. It is surprising what people can eat with impunity provided they take it slowly and chew it until if is reduced to a fine pulp, almost a liquid in fact, in the mouth. When staying at an hotel some time ago I met a gentleman of seventy who told me that he had never known all his life what it was to have a pain or a discomfort in his stomach. And his looks bore out his statement. Yet he would take most things that were set before him, but he ate them with a deliberation that is seldom met with nowadays.

One has only to go into any restaurant to see crowds of men eating their food like ostriches, but without the digestion of an ostrich to deal with it after it has been swallowed. The rush and hurry of these days have caused meal-times to be looked upon as necessary nuisances, an unavoidable interference with the day's work, rather than as a vitally-important function, and an opportunity for a congenial rest. Men get into such a habit of hurrying when at their 
business, that they attack their meals in the same manner, whether there be any need for haste or not. And if the urgency of their work is such as to curtail the time required for lunch or dinner, it would do them far less harm and vastly more good to take half the meal quietly instead of bolting the whole lot. Every bite that is swallowed without being masticated is a nail in a man's coffin. And as we have seen already, this applies to soft foods as well as to those which are of a more substantial nature.

When mastication is imperfect the starchy foods do not get their meed of saliva, and when meaty ones are taken in the same way, they are swallowed in too solid a form to be acted on by the gastric juices in the stomach. Indigestion results, and this means that the eatables lose their power of nourishment, and, what is even worse, become tainted with poison. Then there is not only trouble in the present, but even greater trouble in the remote future, which, if it gets beyond a certain stage, may baffle all the resources of medicine to put it right.

Yet few people will acknowledge to this bad habit. It is only when they are persuaded to take special notice of their manner of eating that they can be convinced of the fact. They resent the imputation that they are eating incorrectly. "We always live on plain, healthy food," they say. Quite so; but the healthiest food can become a menace if taken in the wrong fashion. They scoff at the people who go in for a number of courses calling them gourmands. Yet many 
a man who takes a simple dinner, meat and vegetables followed by pudding, actually takes more than those who indulge in a greater variety of courses, but much smaller ones.

Strange to say, many people who often suffer from indigestion after their simple fare at home can go through an hotel menu Intervals without any bad after-effects. It between is because the latter provides a bites. greater number of intervals. When people are taking their two-course dinner in their own homes they are eating all the time, except for the interval between the meat and the sweet course. The action of the stomach is very much like that of a concertina. It needs to contract and expand regularly, and if little interval is allowed to elapse, it does not have the chance of doing so.

This concertina motion also demands an interval between the separate bites, and it gets it if the diner has company, and is obliged to converse during the meal. If it is eaten in silence, as happens in the case of those condemned to live alone, these intervals are lacking. In such a case the only remedy is to be found in reading a book or paper while taking the meal. It requires a tremendous force of will for a man to eat carefully and slowly when alone. He gets tired of the sound of his own jaws. If he is occupied in reading, he is much more likely to take his food in a more leisurely manner.

There is no habit more difficult to eradicate than this of rapid eating, and it needs constant 
care and attention, and we might add " practice," to get rid of it. The point is to avoid drinking too much liquid with the meal, and never to drink until the food has been swallowed. Otherwise it is washed down before it is in a fit state.

It is many years since a well-known physician advocated the custom of taking thirty-two bites at each mouthful before swallowing it. $\mathrm{He}$ probably selected this figure as representing the total number of teeth in the adult jaws. Yet twenty-two would probably do as well. It does not follow that if this plan is adopted we shall have to go on counting at each meal for the remainder of our lives. The habit of mastication would soon become so automatic that we should not need to think about it at all.

Another point to keep in mind is to put down the knife and fork or spoon between the separate bites. This is of great importance, as it ensures the requisite interval being obtained.

An excellent plan is to eat hard crusts without taking any liquid. It is impossible to swallow crusts until they are thoroughly masticated, at any rate without suffering pain in the throat. A little practice at this each day will soon inculcate the habit of eating other kinds of food in a proper manner.

In the case of children, and perhaps of adults also, a good method is to insist on all food being. taken with a teaspoon. This will generally be found efficacious.

Whatever method is adopted, nearly all cases of dyspepsia, except those due to some disease 
of the stomach, can be cured by this means alone.

One essential, however, is the possession of good, sound teeth. And no artificial teeth that were ever made are equal to the Sound natural ones. Every effort should teeth. be made, therefore, to keep the latter as long as possible.

This can be done only by frequent brushing. People sometimes ask whether they should brush their teeth in the mornings or the evenings. There is only one answer, "Both." We might also say, "And after each meal in addition." It is very little trouble, for it takes but half a minute at the outside. And it is well worth doing this, if it means that the teeth can be preserved.

There is nothing so good as a powder to clean the teeth, the mechanical friction removes the particles of food more efficiently than any liquid or paste can do.

Of course, if the teeth are really bad they are better taken out and supplanted by artificial ones. Yet at the best these are like crutches; we must have them if we cannot walk without their aid, but that is the most that can be said for them.

Sound, healthy teeth are important for more reasons than that of mastication. For if they are allowed to get into a bad condition, a virulent poison is developed in their sockets, which destroys the virtues of the saliva, and also gets down into the stomach, still further hindering digestion. And its evil deeds do not end in this, 
for it is absorbed into the system, every part and organ of which feels the effects of its baneful influence.

It is only by constant and scrupulous care that this disease, pyorrhœa by name, can be prevented in the case of those whose teeth are in an unsatisfactory condition. And if they have got to this stage of decay, it is infinitely better to have them all out. For it is not a disease which acts by fits and starts. On the other hand, it is there, like a lurking demon, working its subtle process of pollution all the time, night and day alike. And while it is better to have natural teeth than artificial ones, the latter are vastly to be preferred to a poison manufactory.

It is just because of the persistent way in which this mischief acts that it forms one of the deadliest foes against which the human body has to contend. Its malign influence is so continuous and so allpervading that it becomes one of the most potent factors in predisposing to breakdowns. No sacrifice, either of time or money, is too great that will help to prevent it or keep it in check. 


\section{CHAPTER IX.}

HOW MUCH FOOD TO TAKE.

Speaking generally, the amount should be sufficient to keep the body well and active, but not to load it up with more than it can get rid of.

As to the actual amount, there is no guide save that of personal requirements. Some people need more than others, and without

Personal any reference to the size of the require- individual. A little man may easily ments. require twice as much as a big one. It depends on the rate at which his system burns it up. It is of no use, therefore, to judge of our own needs by those of other people. A noted big game hunter is said to be able to take three full-course dinners in immediate succession, without the slightest inconvenience or any apparent detriment to his health. Such persons can be regarded only as freaks, and any attempt on the part of others to imitate their example would lead to disaster. For we could no more follow his lead in this respect than we could do what he is also capable of, namely to go for three days and nights without food or drink, and feel no worse for so doing.

Appetite will usually be found a sound guide, 
provided that it is not satisfied to the point of repletion. It is always well to eat Appetite. steadily and moderately, following the time-worn plan of rising from the table feeling as if you could eat more. Sometimes a man will sit down as hungry as a hunter, attacking his viands with avidity. Two hours later he wishes that he had not. He has taken more than his digestion can cope with, and the result is that for a day or two afterwards he can scarcely eat anything. If there is an excess of appetite, so to speak, left over, it will keep until the next meal. Regularity in amount, as well as in times of feeding, is essential to health.

As a rule people eat too much, and need to be reminded of the fact, tactfully of course. It is astonishing to watch the improvement in health and energy which often follows a reduction in the amount of food taken. Many listless, tired patients become bright and vigorous after they have been persuaded to adopt this course. It is not uncommon to see thin people who have been overfed by their anxious relatives, and have become sallow and dyspeptic in consequence. In such cases it is difficult to convince the individual himself, and still harder to convince his friends, that he will not become thinner if he takes less food. Yet practical experience has shown that he not only fails to lose weight, but in many cases even puts it on.

A physician once experimented with two men of this type, pallid, seedy young fellows, both of them. He kept them under his care for six 
months, giving them one-third the amount of food they had been accustomed to, and making them take three times as long in eating it. By the end of that period they had grown into strong, lusty chaps, two stone in weight heavier, and with a fine healthy colouring in their cheeks.

The average diet of the Anglo-Saxon is vastly in excess of his needs. Especially does this refer to the amount of food taken on

Excess of Sundays. Why we should choose food. to celebrate the Sabbath by eating more and taking less exercise is a mystery. We often meet with people who complain of feeling "Mondayish," as they call it. They think it is due to the reaction consequent on resuming the week's work, whereas it is nothing more than the fact of their having eaten too much on the previous day. For many people who are abstemious enough during the week-days take more at every meal on Sundays. They have something extra for breakfast, and take it at a later hour than usual; they have a hearty dinner midday, and take cake and jam for tea, completing the day by a hearty supper, in which cold meat and pickles generally take a large share. And all "because it is Sunday."

Now if such persons can be prevailed upon to make a light breakfast, eat moderately at dinner, limit their food at tea to a biscuit or a piece of bread and butter, and finish up with a rational supper, they-will find that on Monday mornings they are as fresh as on any other day of the week ; in fact, probably much fresher. It would be a 
good thing for the community if people would make Sunday a day of rest in regard to diet as well as other things.

In speaking of butcher's meat, we pointed out that less of this is necessary in the case of people approaching middle age. The

Diet at same remark applies, though not middle age. with the same urgency perhaps, to food of all sorts. As people grow older the system loses some of its power of throwing off the residue of waste matter, and it is of vital importance, therefore, that people should exercise even more care and discrimination than at any previous period in their lives.

Yet as a rule they tend to eat more rather than less. And the consequent strain upon the system is the starting-point of many a breakdown. For not only is the system less capable of eliminating the waste, but the various organs have less power to support each other when any of them suffer in consequence of the extra effort demanded of them.

The question of a suitable diet for stout people is one that bulks largely in the mind of the public to-day. At one time the neurotic

Diet for patient was always supposed to be the obese. thin. It was the fat ones who kept people alive and in a good humour. It was all a myth, of course, and there was no truth in it. It is all very well to talk about "Laugh and grow fat," but whether fat people are addicted to laughing is another matter. For gradually it began to dawn upon the world that 
they were rather a heavy, stolid set of folk after all.

Then, to its surprise, it found that stout people are more liable to neurasthenia than thin ones. In any medical paper to-day you are almost sure to see an article on neurasthenia and obesity.

The result of all this has been that there are more people wanting to get thin than thin people desirous of getting stout. The question is how they are to do it. It is generally supposed that it can only be achieved by eating less. This is quite correct in one way. They must eat less, but of certain articles of diet. It does not follow that they must always rise from the table craving for food. It is a healthy custom, as we have pointed out, for people to get up from the table feeling that they could take more, but for some to be doomed constantly to leave their meals as hungry as when they sat down would be a hardship that few would submit to.

Fortunately this is not necessary. It is not so much the quantity of food as its quality which accounts for putting on flesh.' There are certain articles which are fattening, not only because of what they consist of in themselves, but also because they tend to make other items give up the fat they contain. The important point is to avoid these foods. It must be made clear, however, that a certain amount of laxity may be allowed. There may be some of Falstaff's dimensions who may find it necessary to carry out the diet to the letter. It may be a matter 
of urgency, perhaps of life itself, that they should be brought down in weight, and without any loss of time.

But there are others who feel that a certain reduction is desirable, but not to the same degree as these others. And such people, while following the general principles, need not deny themselves so completely as the stouter ones.

Speaking generally, the foods which tend to put on weight are the starches, such as bread and potatoes, sugars and fats. The following list contains firstly those articles which have this tendency, and then those which can be taken with impunity.

Articles to be avoided.-Cream and butter. Bread, teacakes, scones and cake of all sorts. Porridge. The fat of bacon, ham or any other meat. Eggs. Red fish, as salmon and mullet. Potatoes, turnips, carrots, parsnips, artichokes and all other root vegetables. Puddings of all kinds. Pastry, sweets, jellies, jam and sugar. Apples, pears and bananas.

The following may be taken.-Tea and coffee (but not cocoa). Milk in strict moderation. Dry biscuits, such as cracknel. Lean ham, bacon, tongue, white fish, thin soup, fowl and game, and the lean of butcher's meat. Green vegetables, cabbage, cauliflower, spinach, tomatoes, peas, beans, asparagus. Cheese may be permitted in small quantities.

Water should be taken apart from meals. If taken hot before meals it has a reducing and beneficial effect. 
It will be seen from this list that there is no reason why anyone wishful to reduce their weight need complain of a lack of food wherewith to satisfy their appetites. Yet, if adhered to, the diet rarely fails to bring about the desired result. 


\section{CHAPTER X.}

\section{WHEN TO TAKE FOOD}

Punctuality at meals is absolutely essential for the maintenance of good health. The stomach gets into the habit of secreting its

Punctuality. digestive juices at certain times, as meals fall due. If it does not meet with the food it has come to act upon, it will seize upon the stomach wall and cause pain and a nauseous sense of sinking. And these sensations will probably be followed by a headache, for the gastric juice, which is one of our vital agents, is nothing less than an irritant poison if it has no work to do. It is like a man loitering about an office or workshop when trade is slack. He has gone there to work, and when he finds nothing to do except to hang around and put in time as best he can, he becomes dissatisfied.

More than that, it is only too likely that if this goes on for several days the man will fail to turn up one morning. As there is nothing for him to occupy his time with, he thinks he might as well stay away. And that is exactly what the gastric juice does under similar circumstances. If people have been accustomed to take dinner at one o'clock each day, and for several days in succession turn up an hour late, they will find that they begin to suffer from indigestion. The gastric 
fuice has got tired of making its appearance a.t the proper time; as it has been treated with contempt, it takes its revenge by staying away. There is a form of gastric derangement known as Commercial Traveller's Dyspepsia, which is due solely to the fact that with these members of the community meal-times must be constantly varied, owing to the exigencies of their work, and the vagaries of railway trains.

Of course, it may be necessary at times to make an alteration in a meal hour. When the light summer evenings come, many people prefer to change the hour of the evening meal, in order to enjoy walks or outdoor games. If, however, the new hour is adhered to, the stomach soon learns to adapt itself to the change. It is the constant chopping and changing about from day to day that has such a pernicious effect on the system.

There is another member of the community who is liable to suffer from the consequences of irregularity in regard to the midday meal. It is the woman whose husband cannot get home to lunch, so that she is left to take it alone, unless she has children to cater for. We confess to having less sympathy for her than for the aforesaid commercial traveller, for it is not the fault of the latter that he does not get his meal regularly at its proper time, while in the case of the woman the blame lies entirely with herself. She takes that deadly "something on a tray," and takes it at any time that suits her convenience. Probably she has had a breakfast of tea and bread and butter. Too often the same fare appears for her 
lunch. There is little wonder that often she is a martyr to dyspepsia and headache.

The question as to the length of the intervat between meals is an important one. And here, in particular, individual requirements

Interval enter largely. Some people can go between for a considerable time without food meals. and feel better for so doing. Others feel sick and unduly tired if they fast too long. It rests with each one to find out what suits them best.

On general principles, however, if an interval is too short there is a likelihood of a certain amount of food being left over still undigested from the last meal. And this interferes with the work of the stomach. Under such circumstances the tongue is liable to be coated with a thick fur, and the individual to suffer from a constant feeling of nausea.

If, however, the interval is too long, the system has become exhausted and the stomach goes on strike. By the time the meal is taken, the supply of gastric fluid has failed. If a long interval between any two meals is unavoidable, as for instance where a man has to have his breakfast at eight and cannot get his lunch until half-past one, it is better to take some light food in the meantime. This prevents the sense of exhaustion, and does not hinder the stomach from doing its work when it is called upon. Otherwise the man is apt to get a headache before he gets his meal, and indigestion after he has taken it. 
This is a very different matter from the habit of eating between meals, whether it be in regard to sweets or to heavier articles of diet. There is a form of hunger known as "false." It comes on an hour or two after meals, and is due to the irritation of undigested food in the stomach. As it is often accompanied by a sensation of sinking, people sometimes take some food, such as beef-tea or strong soup, to keep themselves up, as they term it. The result is confusion worse confounded, and if the process is repeated too frequently serious damage may be inflicted on the digestive organs.

I have dealt at considerable length with this question of diet, simply because it has such an important bearing on the subject

Diet and of breakdowns. There is no single breakdowns. path that leads to breakdowns, the way thither is rather a tangled maze of paths, along which people stumble blindly until they suddenly find themselves at an impasse. Yet the point at which they first left the high road of health consists in most cases of a mistake or series of mistakes in regard to their food and the manner in which they take it.

The digestive troubles of the present day are very different from those of a century ago. "The fine old English gentleman, The old one of the olden style," consumed style. an enormous breakfast and a still more enormous dinner, washing down vast quantities of food with great draughts of beer or wine. Every now and then he was 
laid up with a stomach-ache or an attack of gout, and for a day or two made the welkin ring with his upbraidings; then he turned up again, as fresh as any young buck, and went on his way rejoicing until the next attack laid him by the heels.

We marvel that he survived to tell the tale. "I should be dead in a week if I did such things," one of my readers probably remarks. Yes, but the hale old chap led a different sort of life from that which we lead to-day. He spent most of his time in the saddle or in walking about the countryside. Moreover, the food he ate was of such a solid nature that he was bound to chew it well before he could swallow it. And the bilious or gouty attacks from which he suffered afforded a welcome respite to the whole system, giving it the chance to throw off a large amount of deleterious matter.

There is no comparison between such a process as this and the continued remorseless poisoning from which many people The present suffer in these days as a result of style. dietetic mistakes. And this poison finds an easy victim in the constitutions of to-day. These hearty blades of olden times did not impose much strain on their nervous systems. They lived nearer to Nature instead of cooping themselves up in offices and businesses, straining body and mind in the struggle to make a livelihood or a fortune. All the more reason why we should take infinitely more care in regard to our diet nowadays than our ancestors did.

At a dinner party some years ago one of the guests was a sallow, dyspeptic-looking individual, 
of a melancholy cast of countenance, and with nerves written in large characters all over him. In fact, the state of his nerves constituted the chief part of his conversation, to the utter boredom of the lady he had taken in to dinner.

It appeared that he was always tired and depressed, and could not make out why it was. $\mathrm{He}$ had taken tonics and gone for holidays to various health resorts, but had gained not the slightest benefit.

He might have obtained some glimmering of the truth if he had placed a mirror in front of him as he dined, or even if he had only stopped to think. For he ate rapidly, almost ravenously, of every course that was set before him, bolting it down with scarcely any attempt at mastication, which the present style of preparing food renders only too easy. "He was bound to make a good dinner," he said, as his business was of such an arduous and worrying nature that he rarely had time to get any lunch. At the conclusion of the meal he apologised for taking out of his pocket a box of digestive tablets. He was forced to have them, he explained, as he was a martyr to dyspepsia.

Yet ten years before this man had been a strong, healthy athlete. Now he had become a wreck, and his life was a burden to him. Not only was he incapable of doing his work properly or of enjoying his pleasures, but he lived in a constant dread of a nervous breakdown. And the probability is that unless he has reformed his ways of eating that catastrophe has happened to him ere this. 


\section{CHAPTER XI.}

FRESH AIR.

THE very title, "Fresh Air," conjures up visions of wide-spreading moorlands and foam-flecked seas, of sunny dales and quiet trout-streams, of breezy golf links and bracing mountain-tops; of all the things, in fact, which we are going to revel in when we go for our next holiday.

When we go for our next holiday! And what is to happen in the meantime? For fresh air is a daily, we might say an hourly, necessity, not a yearly luxury. The combustion on which the health so largely depends is always going on. The bodily engine never ceases running from the beginning to the end of life. Sometimes it is more active than at others, but even during sleep itself, though the muscles may be relaxed and motionless, the heart is acting, and the lungs must continue to do their work. The machinery of the body is never still, the furnaces are never out. Sometimes they are burning fiercely, at other times with a gentle glow.

Yet no matter whether it is one or the other, it is necessary that the processes of combustion should be complete, and the purer the air that reaches the lungs, and the more there is of it, the more effectually will this end be attained.

Send a tired, seedy-looking man into the open 
air for a whole day, and even if he only lies down or lounges about the whole time, you may notice the difference in his looks by the time evening has come. His eyes will be brighter and his complexion clearer, and the dragging sense of heaviness in his limbs will have disappeared. Instead of discomfort and nausea, he will have a good, healthy appetite.

As for his nervous system, there will be no comparison. There is no tonic in the whole world for jaded nerves like an abundant

Fresh air supply of pure, fresh air. And if and the sunshine can be obtained at the nervous same time so much the better, for system. the effect of direct sunlight on the body is simply remarkable. Some years ago a new form of holiday was started in the shape of trips to the Sahara, for the benefit of those suffering from brain-fag. The success which attended them was due largely to the free supply of sunshine, not merely to the fact of the patients being away from their work and ordinary surroundings. Many of them had tried rest cures elsewhere without any good result. It was only when they spent weeks in some oasis, with the sunlight pouring down on them from morning till night, that their nervous systems recovered themselves.

Yet these people should never have had brainfag if they had only carried out the rules we are about to lay down.

Most of us are not in a position to go to the Sahara, but we can get at home, if not such a 
flood of sunshine, at any rate enough fresh air, in conjunction with other precautions as to diet and so forth, to prevent our systems ever getting into such a state as to make a trip of this sort, with its outlay of time and money, a necessity.

Apart from sunshine, fresh air has a potent influence on health. We all pine for fine holidays, and no doubt they do us more good, in addition to being more enjoyable, than wet ones. Yet it is amazing how much better people look after even a rainy holiday at the seaside or country. The rest from the worries of business and so forth has something to do with it, but I firmly believe that half the benefit is due to the fact that when people are on a holiday they spend the greater part of their time in the open air.

A friend once remarked to me that he always began to feel nervous and worried as soon as he got back home. He wondered if the district agreed with him. I asked him what sort of life he led when he was in the country. And he replied that he pottered about outside all the time. If it was wet, he put on a mackintosh and went out just the same. Yet he owned up that he never thought of doing such a thing at home.

Two men were walking down a street in the West of London on a winter's afternoon. The one was plodding along wearily with his eyes fixed on the pavement and lines of care on his face. The other held himself erect, walking with easy strides, and looking around with genial eyes that seemed to find an interest in everything they saw. His breezy manner and the glow of health in his 
cheeks were a marked contrast to the look of weariness and pallor on the face of his companion.

Yet these two were brothers, brought up in the same way and under the same conditions. The - one had applied himself to the law, finally settling down in London, amazed that his brother should be content to bury himself in the heart of the country.

A few hours later they sat down to dinner together, and the lawyer looked with envy at the hearty way in which the country brother ate his food, and the relish with which he seemed able to take anything that was set before him. His own appetite was fickle to the last degree, and even when he ate any of the courses it was with a doleful presentiment as to the effect they would have upon him.

It was after midnight before the lawyer could make up his mind to go to bed, and he went with the expectation of a restless night. By that time the other brother was enjoying a deep, untroubled slumber.

Six months later you might have seen those two men again walking side by side. This time it was on an August morning amongst the fields and hedgerrows. The difference between them was not so marked on this occasion. The lawyer held his head higher, his eyes were brighter, and his cheeks had lost much of their pallor. He did not look down at the ground either, but gazed all around him, and some of the careworn lines had disappeared from his face. He had had three weeks of pure, country air, and had spent most 
of it in the open. He was dreading the time, a few days hence, when he would have to return to town.

That was not anything out of the common. We have all seen people returning from their holidays looking like that. The surprising partsurprising even to the man himself-was to follow. For during the following winter you might have watched that lawyer stepping out of his office any afternoon, and would have been amazed to notice that he had never lost the improvement which he had gained during his weeks in the country. His dread that he would sink back into the same nervous, dyspeptic state as before had been unfounded.

For it was only a few days after he had got back to town that he had been talking to a friend and telling him how much better he had felt after his open-air holiday. And the friend had said, "Then why not keep it up now you are at home ?"

That remark had set the lawyer thinking, and the force of it had impressed him deeply. So instead of driving to his office each day he had made a habit of covering the three miles on foot, and returning home in the evening in the same way. He had taken every opportunity of having a walk, either along the streets or in the park, and had felt a new man after it. And it was nct only his bodily health which had benefited; his nervousness had 'zone, and he had ceased to worry over his work and all his other affairs. He had found not only fresh air during these walks, but a vast number of other things to 
interest him at the same time. And the weather did not seem of nearly the same importance as beiore. If it was wet, he took a coat and umbrella and trudged through it as contentedly as if he were enjoying bright sunshine. To his surprise, he did not catch cold nearly so often as he had been accustomed to do.

Now this man only did what anyone else can do, that is to secure a daily supply of fresh air. There are vast numbers of people who would be different creatures if they would have a walk morning and evening, either before breakfast or their evening meal, or on their way to and from their work.

It is of little use, however, to take walks in the fresh air if we come back to badly-ventilated houses. There are some dwellings

Fresh air in which the air always feels dead; in the there is a staleness about it which home. offends our nostrils the moment we cross the threshold. The doors and windows are kept closed, and the whole house reeks of the accumulated poison from the lungs of those who have lived beneath its roof.

In a north country dale there is a charming cottage, its latticed windows framed in creepers, standing back from the village street. It is the admiration of all beholders, yet its beauty is only the shell that hides a grim tragedy. There were five children in the family, and one by one they died of consumption. And if you examine the pretty latticed windows more closely, you will find the secret of their fell disorder, for not 
one of those windows, upstairs or down, will open. Those youngsters played in the fresh air, they went to school and returned home in it, but every minute that they spent in the house they were living in a poisoned atmosphere. If there had been no such thing as bedtime, they might have escaped; but it was no wonder that when some tubercle bacilli made their way into that house they found easy victims in the innocent, sleeping forms of those children. For even the fireplace in the bedroom was blocked up with a sack of shavings.

An atmosphere of that sort is like a two-edged sword, it cuts both ways. It not only lowers the resisting power of the human body, but also favours the growth of germs. And consumption is not the only complaint to which vitiated air may lead. There are many other forms of ailments which, if not so deadly as this disease, exercise a most pernicious influence on health.

Common colds play a far greater havoc with the health of a nation than is usually supposed. For it is not merely the loss of time spent in getting rid of them, but the infinitely more important fact that these chills and catarrhs upset digestion, lower the general health, and lay it open for deadlier enemies to enter. Sometimes colds are of the influenza nature, the result of a germ, which may fix itself in the throat in spite of all precautions. Yet the influenza bacillus itself finds the greatest ally in any catarrh of the nose or throat. We frequently hear people say that they had an ordinary cold which developed 
into influenza. It is a perfectly true statement, and if the ordinary cold had not been there first, it is more than probable that the influenza germ would not have had a chance of establishing itself.

Nothing causes chills more than hot, stuffy rooms. We often hear people complaining that they took cold when they came out into the night air. Yet it was not the night air which did the mischief, but the poisonous atmosphere in the room itself, due to the accumulated exhalations of many lungs, etc. Had the apartment been well ventilated the so-called chill would never have occurred.

Most cases of asthma are the result of a bad atmosphere. The catarrh has extended down from the nose and throat into the bronchial tubes, and set up a spasm which is the source of this distressing malady. No asthmatic can afford to keep his windows closed. Whether by day or night, he needs a liberal supply of fresh air.

It is not so much by day that people suffer from the effects of poor ventilating. For then most of us are compelled by the force of circumstances and the exigencies of our work to move about from one place to another, even if it is only from room to room. It is in the evenings, and winter evenings in particular, that the atmosphere of the dwelling-rooms becomes contaminated. The family sits by the fireside, with the windows and door closed, and they never notice how stuffy and close the room is becoming, until someone comes in from the outside air and beseeches them to open the window. 
Yet they go on sitting in that poisoned air. and one or two of them become drowsy and sit half asleep, with the result that when bedtime comes they have to face a restless night. Others, perhaps, find their heads aching, and attribute it to the fact they are working too hard during the day.

But it is only when they go to bed in rooms with the windows closed that the chief harm comes. Considering what a large proportion of our lives we spend in our bedrooms, it is of vital importance that the air should be, if anything, purer than that of the rooms we live in by day. For at night we are not moving about, but lying still, and the air does not get a chance of renewing itself unless the ventilation is efficient. Many people complain that they can scarcely wake up in the mornings, they feel so heavy. Or that when they do rouse themselves they have a headache, which it takes hours to get rid of. All this might be avoided by the use of the open window.

The objection to it generally consists in the fact that it makes a draught. There is no necessity for this, however. There are some cranks who have much to account for in regard to this matter. They boast that they can sleep close to a window which is open top and bottom to its fullest extent, and are proud to say that they have waked up in the morning to find that the rain had been coming in and had soaked the bedclothes through and through.

There may be a few constitutions which can 
stand this, but they are certainly in a hopeless minority. The majority of people would find themselves in "Queer Street" if they attempted such folly, for folly it is without a doubt. In one case where a father adopted vigorous methods of this sort with his children it ended in one of them getting an inflammation of the ear, which resulted in incurable deafness.

There is reason in all things, ventilation included. And fresh air can be secured without any draught at all. A few inches top and bottom, or only at the top if the weather be very stormy, makes all the difference, either in a sitting-room or a bedroom. Better still is the plan of fixing a block of wood the width of the window frame below the lower sash. That leaves a space between the upper and lower sashes, which ensures a constant supply of fresh air. If this be adopted the atmosphere will always be pure and healthy, even if the window is never opened any farther.

It is vastly better to have this constant supply of pure air in small doses than to throw the window open wide after the atmosphere has. become hot and unpleasant.

Sometimes, however, it happens that in spite of all our efforts we have to breathe air containing some deleterious matter, germs or dust or whatever else it may be. To meet this contingency, Nature has provided a filter of her own. It consists of a network inside the nostrils. That is why it is of such importance to breathe through the nose instead of the mouth. If all children 
were taught to do this there would be fewer colds and fevers. The nostrils would arrest the unwholesome particles before they had a chance of reaching the tonsils, which are such a suitable soil for their growth.

Needless to say, pure air is of greater value when it is inhaled as freely as possible. In order to bring this about, it is necessary to breathe deeply. There are not many people who get the best value out of their lungs. As a rule, respiration is much too light. In order to remedy this defect, breathing exercises are of great value. The way to carry them out is to stand with the hands on the hips and breathe slowly in and out, inwardly counting four each time in a deliberate manner, and expanding the chest to its fullest possible extent.

The mistake usually made is to lift the chest with each inspiration. This only raises it, it does not expand it. The proper way is to breathe from the abdomen and lower part of the chest wall. When this is done every part of the lung is filled with air, and this has the great advantage of preventing the air inside the lung spaces from stagnating in any one part, an occurrence which is always prone to lead to the onset of congestion or disease.

It does another good turn too, for it inculcates the habit of deep, full breathing. Those who practise for a few minutes each day will soon find themselves expanding their lungs habitually, even when they are not thinking about it.

Yet even if windows and doors are kept open, 
something more is requisite. For unless a house is scrupulously clean and the rooms Cleanliness regularly turned out, it cannot be in the healthy. If a piece of machinery house. is left untouched for some months it will never be as good as it was before. The grease has become foul, whilst dust and dirt have accumulated, and these insidious elements have combined to destroy the quality of the metal. That means that some time or other some bar or joint or nut will crack, and once that has happened the mischief rarely stops there, but goes on to the weakening of other parts and the deterioration of the whole machine.

And when human beings live in houses that are not fresh and wholesome they are constantly inhaling dust and fusty smells, which act as a slow, subtle poison and lower the vitality of the various tissues of the body. It is so gradual that they may not notice it, until at last something gives way, and after that the downward tendency becomes comparatively rapid. When the cataclysm occurs, they date it from the day when the first crack, if we may call it so, appeared. Rather should they look back to the long years spent in an unhealthy atmosphere within their own homes.

There is no fault, however apparently trivial it may seem, in matters of hygiene which does not add its quota towards the final

Hygiene in breakdown of thehuman machinery. the home. The faulty, leaking gaspipe which causes oft-repeated morning headaches; the shoked-up scullery sink, with its 
abominable mixture of soap, grease and vegetable washings; the defective drain and pipes; each and all do their evil part in undermining the constitution and rendering it more prone to the onset of disease.

There is another aspect of this question to which too little prominence has been given. It is that of tidiness, and its effect on the nervous system. We all know that a tidy desk indicates a methodical, well-regulated mind, and that one which is in a litter is usually the sign of a man whose ideas are confused and jumbled up. Everyone does not realise that the sight of a disorderly room, with waste paper lying on the floor and an unswept hearth, has an irritating effect on the nerves of a man or woman who comes home jaded and tired.

We shall have occasion shortly to point out that it is this harassed state which is one of the most potent factors in causing nervous breakdowns. And it is just when the home-comer needs to have everything as smooth as possible to put him or her into a calm and equable frame of mind that their fretted nervous systems are still further irritated by signs of disorder in their homes. Tidiness is more than a mere virtue, it is an indispensable adjunct to health.

All who wish to be well, and feel well, and keep well, must seek a free and constant supply of air, and strive to obtain it in all its freshness and purity. They must secure it at all times too, at home and away, indoors and out, summer and winter, day and night. If everyone were to do 
this, the effect on the health and welfare of the nation would be incalculable. They will find it no irksome duty, for before long they will acquire a taste, a longing, we might say a craving for it which will make them wonder how they ever managed to live without it.

An appetite for fresh air is one of those propensities we can indulge in without any fear of going to excess. We can revel in it, gourmandise on it, smack our lips over it, and the more we get of it the better we shall be. 


\section{CHAPTER XII.}

\section{EXERCISE.}

Several men were riding home together in a tramcar on their way from business, and were discussing their health, as so many people do nowadays. They were all looking tired and depressed, and on comparing notes found that they were all suffering from the same complaint, "nervous exhaustion due to overwork." At least, that is what they called it. They were tired when they went to bed, and just as tired when they got up in the morning, and had no energy for their day's work. Why the latter should have proved too much for them was a mystery, as their hours were not long by any means, and they were all in the prime of life.

As a matter of fact, they were not suffering from nervous exhaustion at all, but from poisoning, the result of a sedentary occupation and want of exercise. These men had an excess of waste products in their system, retarding their digestions and clogging their energies.

It is particularly at or just before middle age that the want of exercise so frequently manifests itself. Most people keep up their

Exercise at games or their walking until the middle age. age of thirty or forty. It is after that stage that they tend to settle down and take things easily. If they would only 
reduce their diet at the same time little harm might accrue, but unfortunately in many instances, as we have already pointed out, they begin to eat more instead of less. The result is that we are confronted with the problem of increased intake and diminished output. We often see men of strong physique who have given up games and reduced their walking to a minimum, and have become moody and irritable, sleepless and depressed.

This is because their systems have become loaded with a superfluity of waste matter. And the latter not only makes them headachy and tired, but if the accumulation is allowed to go on unchecked, it deranges the vital organs, the kidneys particularly, and before long may actually set up organic disease. After that the strain on the whole bodily functions becomes greater and greater, until the breaking-point is reached. For as people grow older their organs have less power of throwing off waste material, and become less able to support one another when any weakness appears.

These breakdowns are the most liable to occur in the case of athletes who have been accustomed to severe and active exercise all their lives. In them the system seems to have learned to depend, even more than in the case of other people, upon hard exercise to keep it in good condition. And when men of this type drop it too suddenly, the results are disastrous. Yet that is what so many of them tend to do. They are unable any longer to indulge in the violent games and training to 
which they have been accustomed, and they will not "lower themselves," as I have heard it expressed, to take part in milder forms of recreation. Sometimes they even become too lazy to walk.

Of course, no man can be expected to keep up his running, or take part in boat races, or practise putting the weight after he has passed a certain age. Nor would it be good for him to do so. Once he has passed thirty he must begin to take things a bit more slowly, and avoid taking part in athletic contests. For racing in any form involves a mental as well as a physical strain, and few men beyond that age can stand the stress of the two combined.

Yet if he cannot race he can still row or run or whatever else it may be. Later on he may have to give these up also, and take to quieter forms of exercise. The secret lies in the gradual dropping off. And no man need complain, for there are plenty of outdoor games suited to every age and every constitution.

The great point is that everyone, men and women alike, must have exercise of some kind or other. For most of the vital

Value of processes of the body depend upon exercise. it. It is the chief agent in burning up the waste matter in the system, reducing it to such a form as is most easily excreted by the different organs. It also keeps this waste on the move, and so brings it more freely into contact with those organs. Furthermore, it stimulates the action of the heart and lungs, and so invigorates the circulation, and 
supplies the respiratory tract with a more liberal allowance of oxygen.

Then, freed from the incubus of the presence of this poisonous matter, the digestion improves, and the nervous system regains its wonted vigour once more.

To be efficient, exercise must be steady and regular. A long tramp or a violent burst of tennis or some other game once a

Regularity. week can never make up for days of comparative inaction. More than that, it is almost dangerous. The waste products have meanwhile accumulated to such an extent that, if they are suddenly stirred up, they are apt to produce a severe headache or a bilious attack. People are often puzzled and discouraged when after a long walk on a Saturday afternoon they feel so done up as to be unfit for anything for the next twenty hours.

The exercise should be daily, so that the waste matter is eliminated regularly. To realise the difference between this method and the one we have just been discussing, notice the effect of dusting a room once a week compared with doing it each day. It is the difference between an almost imperceptible quantity of dust and a cloud that fills the room and threatens to choke you.

There is one result of irregular exercise that needs to be referred to here. It is cramp. This painful complaint is due to a

Violent deposit of waste matter in some exercise and muscle, which it causes to contract cramp. violently owing to the local irritation set up. It is liable to occur 
after hard or prolonged exercise of any sort, especially in those who only take it now and then. Sometimes, however, it is found in those who never take part in games, as in elderly people, for instance. In this case it is often due to the habit of walking beyond the ordinary pace. There are some temperaments which never allow their possessors to walk quietly, even though age or some infirmity demands it, and such persons are very liable to wake up at night suffering from cramp.

The treatment is to avoid too violent exercise or to walk in a more leisurely fashion, as the case may be. When it has come on, the remedy is to rub the affected part vigorously, or put it into hot water if such is available.

Exercise, like all other indispensable things in this world, needs to be carried out with discretion. Because a lusty young fellow of Outdoor twenty finds that a hard game, such exercise. as football, once a week, in addition. to steady daily exercise, suits him, it does not follow that it is going to be of benefit for a man of forty. It is an important point in selecting a game to choose a suitable one. Golf is often advocated as the ideal recreation for middle-aged men. Yet one has known of cases where a round of golf left a man jaded and tired, but a game of bowls or tennis did him a world of good. The one might require as much as the other, but for some unknown reason it was better adapted to the needs of the individual in question. At the risk of offending every golfer in the country 
-and that is about every other man you meetI have no hesitation in saying that even if a man does not play it he may be " a man for a' that." And if it only worries and tires, instead of refresh'ng him, he is vastly better advised to leave it off, and take to something that suits him better and is more in accordance with his feelings.

Half an hour a day spent in walking, cycling or playing some outdoor game is sufficient to. keep the whole system in good working order.

Games have the advantage of adding the stimulus of competition and complete change of thought, but there is no better exercise than that of walking. And after all the change of thought can be obtained equally well at the same time, if people have some outdoor hobby, as botany or natural history. It also provides change of scene, which is a fine mental tonic in itself.

The ideal form of recreation is to cycle to some spot, leave your machine there, and set out for a walk. By such means you get far away from your ordinary surroundings, and also receive the benefit of the pure air of the meadow or the mountain-top.

There are many people, however, who live in towns, and, in winter especially, cannot reach green fields or hills except when on The a holiday. There are wet days too pavement on which a country walk is hardly walk. possible or even desirable, on account of the state of the roads. Yet there is another form of walking which is of great value under such circumstances. It is 
what we may term the " pavement tramp." An hour's brisk walk of this sort is an invaluable boon to town-dwellers on a dull day or a wintry night, when circumstances stand in the way of any other form of exercise.

At times even the state of the pavements, as in snowy weather, may render this impossible. In that case, if you are feeling stale and unprofitable, and longing for some active exercise, you may obtain it by walking briskly up and down the stairs. The servants will think you have gone mad, but as they probably think that already, this fact need not deter you from this form ot invigoration.

When people who have previously neglected exercise start to take it, they are often met with one difficulty. They complain that On starting after they have walked for a mile exercise. or so they are too tired to go any farther, and when they return home they do not feel refreshed but rather the opposite. Under these circumstances we need not hesitate to assure them that if they will but persevere, this feeling of fatigue will pass off, and a sense of enjoyment and lightness take its place. Once they have experienced the truth of this they are ready to continue the daily walk and exercises, and soon begin to wonder how they ever managed to live without them.

This acute fatigue is due to the stirring up of the waste matter in the system. If, however, they force themselves to keep on walking quietly, the exercise itself will help to eliminate these 
undesirable elements, and so fulfil its most important function.

This question of exercise calls for special mention in the case of women of the middle and upper classes. Too often their exercise for the day consists in shopping or paying calls, neither of which are conducive to health. The constantly recurring headaches from which many women of this type suffer might be cured, along with the observance of the other rules of health, by the observance of a daily walk and gentle exercises within their own homes.

Indoor exercise is the department in which so many people go wrong. A young man is convinced of the necessity of keeping

Indoor himself fit, and the way in which exercise. as a rule he sets about it is to practise with a pair of heavy dumb-bells before breakfast, or else to buy a developer and use it, for the purpose of getting his muscles up.

Now Mr. Sandow himself has always been the first to warn people against the abuse or over-use of the developer, and against practising with heavy dumb-bells. I was once amazed to hear that great authority say that he could keep his muscles in perfect condition with two-pound dumb-bells. Little wonder, therefore, that men of ordinary physique find themselves, after a quarter of an hour with seven-pound ones, stale and tired for the remainder of the day.

We have to bear in mind that the most important muscle in the body is the heart. 
Cases are not uncommon in which young fellows have developed their limb-muscles at the expense of this vital organ, with the result that they have been more or less incapacitated ever afterwards. It may be very delightful to possess a biceps twice as large as your neighbour's, but beyond the gratification of contracting it for their approval there is nothing to be gained, unless you are going to be a navvy, that is to say. And that is not likely to be the case with any of my readers, for navvies are not in the habit of perusing books on health. They do not need to do so:

If a man needs certain muscles specially strong for his work, his work will develop them for him. Otherwise they are of little use to him, and he had better conduct his exercises on a sounder principle.

The main object of physical exercise is to keep the whole body fit. In choosing suitable ones, therefore, it is necessary to select Object of those which call upon all the exercise. muscles of the body without any undue strain upon any particular set. If any one group is over-used there will come a time when they will begin to waste away. It is well known that in certain occupations which throw great strain upon any one part, such as the arms in the case of porters, who have to be lifting heavy loads constantly, the muscles of these regions enlarge enormously at first, but often degenerate after a time, until at last the limbs in question may be reduced almost to skin and bone.

The best form of exercises for purposes of 
general health are those known as Swedish. No dumb-bells are required, though Swedish many people find it easier to exercises. practise them if they have a piece of wood in each hand. The number of systems included in this category is legion, and people are often perplexed to know which one to choose. Some friend recommends one set, then another comes along and says that he has derived great benefit from a different set, and a third strongly advocates some other. The fact is there is no advantage in any one over the rest. All are equally efficacious; the great point is to do exercises of some sort. You can easily plan out a set of your own, which will do quite as well as any other.

Whichever are chosen, it is well to do them gently at first, and for a short time only, gradually increasing them as you become more accustomed to the movements.

A good selection to start with is as follows. Stretch out the arms in front, with the finger-tips touching those of the opposite hand. Swing them slowly backwards as far as they will go. Stretch them out again in the same way, and try to touch the toes, keeping the knees straight. Place the hands on the waist and bend the body forwards as far as possible and also from side to side. Lie on the floor and raise the body without the aid of the hands and with the knees stiff. Stand erect and raise onewleg slowly, balancing on the other foot.

A few simple exercises such as these are quite sufficient to keep the whole system in good 
order. Complicated or difficult ones are never necessary. The one great point, more important than all else, is to attend carefully to the breathing while making the movements. Take deep, slow breaths, expanding the chest fully and exhale slowly, always breathing through the nose. If you get out of breath you are either doing the exercises wrongly or breathing in an incorrect manner.

In addition to the above, you can devise fresh ones as you go along. A good plan is to take each joint in turn, and exercise it. Thus, start with the fingers, clasping and unclasping the hand. Then clench the fist and move the wrist up and down. Do the same with the elbow and shoulder, and with the different joints of the lower extremities. Then bend the body backwards and forwards, and the head in the same way. After all that, there will be few muscles in the whole body that have not received their due attention.

The value and the enjoyment of these exercises can be increased very much by getting other people to join you in them. It is easier to persevere with anything if we have the society of others to encourage us. There is a spirit of emulation introduced which is always conducive to success.

If you are so fortunate as to have an empty room or shed, there is nothing better than to practise an imitation of some out-

Imitation of door game, such as playing tennis games. against a wall. There is a zest about such exercises which makes them more profitable than those which are 
carried on merely from a sense of duty. One of the finest forms of exercise is that of skipping, both for men and women. The former need not look upon it as a feminine pursuit, seeing that some of the best-known athletes and boxers employ it as a means of training.

It is simply astonishing what a difference exercise, either outdoor or indoor, makes to those who carry it out systematically. After a few weeks pale, languid people begin to acquire a healthy colour and a sense of vigour they have never known for years ; dyspeptic ones may forget that they ever had a stomach; whilst headaches that have been a curse for years are sometimes seen to disappear like magic. Life becomes brighter, for health and happiness go together, and the whole outlook becomes more cheering.

All these are active forms of exercise, but there is another sort which needs mention, viz. the passive, or massage, as it is termed.

Massage. Some people either through general weakness or some infirmity are unable to take exercise for themselves, and in such cases massage is of great benefit, acting in the same way, but without any exertion on the part of the patient. The full consideration of this subject would need a volume of its own, and this is hardly the place to discuss it in greater. detail. One important fact, however, requires mention. It is imperative that a prolonged rest of an hour or two at least should be allowed after each rubbing. One hour of massage is equivalent to several hours of active movement. 


\section{CHAPTER XIII.}

BATHS AND BATHING.

THE skin plays an important part in eliminating waste products from the system. It does this by means of the sweat-glands, which are found scattered all over the body. These glands have small ducts, ending in minute apertures on the surface of the skin. If these apertures are allowed to become blocked up, either by dirt or by the natural grease of the body, the skin cannot carry out its duties. The result is that a certain amount of this waste matter is kept back, and the health suffers in consequence sooner or later.

Neither cold baths nor outdoor bathing can get rid of this grease, so that a hot bath occasionally is essential, even in the

Hot baths. case of people who bathe regularly every morning, either at home or out of doors.

The usual objection to hot baths is that people take cold unless they go straight to bed as soon as they have dried themselves. Otherwise, so they say, they go on perspiring and take a chill. Now this is due, not to their having had a hot bath, but because the water was not hot enough when they got out of it. Hot water has the same effect as cold in bracing up the sweat pores, and 
preventing them from continuing to pour out unnecessary perspiration. Lukewarm water, on the other hand, leaves the skin lax and moist, and it is then that people are liable to chills. Hence the popular idea of running in some cold water before the bath is finished is a mistake, as it brings about the very conditions we are anxious to avoid.

An indispensable adjunct to every bathroom is a thermometer, by which the temperature of the water can be accurately gauged. The common plan of testing it by the hand is fallacious, as the result depends largely on the state of the hand at the time. If the fingers are cold when dipped in, the water feels warmer than it usually is, and vice versa.

The best temperature at which to take a hot bath is $100^{\circ} \mathrm{F}$. or just below that. If more water is added afterwards it should be hot, not cold, so as to maintain the temperature at the same level. With the aid of these precautions it will be found that drying is a simple process, and the skin is left in a delightful state without any undue perspiration to follow. SSo far from causing a liability to chills, it is perfectly safe to emerge from a jath of this sort and take a walk immediately after dressing, even on a winter's day, without suffering from any ill-effects. People sometimes complain that a hot bath makes them feel faint. This is due to the steam, not to the water itself. If the windows are kept open this discomfort may be entirely avoided.

There is nothing more refreshing than a bath of 
this sort, not only in winter, but in hot weather also, as many athletes are beginning to find out. After a hard walk or game it effectually relieves the aching of the limbs, and helps to prevent the stiffness which is apt to follow. The good effect of the bath may be increased by massaging the limbs while they are under water. The proper way to do this is to grip the muscles between the two hands, and squeeze them with a sort of sliding movement towards the extremities, afterwards kneading them a bit at a time.

Hot baths are an excellent remedy for nausea or biliousness. A quarter of an hour in a bath at a temperature of $100^{\circ} \mathrm{F}$. will often be found to remove all unpleasant symptoms and restore the appetite and digestion. They are also a boon to rheumatic persons, helping to banish the muscular pains and general feeling of malaise.

All this they do by causing the blood to circulate more freely, and dilating the vessels on the surface, and in so doing relieving the congestion in the muscles and internal organs. In this way they promote the elimination of the waste products which cause tiredness, fatigue and most of the other aches and pains from which tired humanity is liable to suffer. It is not necessary to wait until bedtime before having a hot bath. Its most beneficial effects can be obtained by taking it in the evening on returning from work. It is then that it is most refreshing, and if made use of at this time of day, will enable many a man who has come home fagged out to spend an enjoyable evening, when otherwise he would be 
sitting down too tired to read or take part in any amusement.

Cold baths do not suit everyone. In fact, there are comparatively few people who derive any benefit from them. Many persons find Cold that if they have one in the morning Baths. before breakfast it leaves them tired, and with no appetite for the meal. They only take them because they are popularly supposed to be invigorating. The proof of the pudding is in the eating. If a man feels well, in a comfortable glow, and ready for his breakfast after them, they are good for him. If he feels otherwise, and does not enjoy the bath while he is in it, they are bad for him. There are some people who dread cold baths, and yet go on having them from a mistaken sense of duty. The only explanation is that they must think they do them good just because they are so unpleasant, in the same way that some people have more faith in medicine if it tastes nasty.

Of one thing there is no doubt. Rheumatic persons and those liable to bronchial affections should never take them under any circumstances. Nor should delicate or elderly people make use of them.

The disadvantage of a cold bath at home is that the feet are chilled before the head. And wetting the hair with cold water The cold does not get over this inconvenience. shower. A shower bath, however, does away with this objection altogether, and on this account there is no form of cold bath equal 
to it. The head can be held under the water first, and after that the bather steps in and the body and limbs receive the shock at the same time, so that the lower extremities are not chilled before the rest. The unfortunate part of it is that so few houses are fitted up with shower baths.

Whatev,r form of cold tub is used, it is advis wive to stay in for a very short time only. Even robust people can rarely stand more than a few minutes of it.

It is generally supposed that a cold bath should be taken when the stomach is empty. Such is not the case, however. While no one would be so foolish as to take it immediately after a meal, yet a drink of hot tea or water just before going in will enable many persons to enjoy and get benefit from them, who could not do so otherwise.

Outdoor bathing, either in sea or river, does not agree with everyone, although some people can enjoy a bathe who are unable to Outdoor take a cold bath at home. The bathing. common mistake is in bathing before breakfast, when the system is at a low ebb, owing to the long abstention from food. It may be all right for strong young people, but for many others it is unsuitable and even dangerous. The best time, as a rule, is about two hours after breakfast, when the body has been fortified by the morning meal, and has had time to digest it.

The great point is to get thoroughly warm before entering the water. A brisk walk is the 
best way of accomplishing this, or if that does not produce the wished-for result, take a hot drink. The body heat falls rapidly whilst in the water, and hence it is advisable to be in a glow before going in.

For the same reason do not waste time over your undressing, and always remove the upper part of the clothing first, leaving the stockings to the last. It is the feet which are specially liable to be attacked by the cold, and it is therefore necessary to keep them warm as long as possible.

Before taking the plunge, pour cold water over the head; simply dabbing the hair with it is not sufficient. After that, get the whole body under water without any delay, and keep it under all the time you are in. It is the evaporation from the surface of the skin which lowers the temperature, rather than the contact of the body with the water.

Do not stay in too long. If you remain until you feel you have had enough, it generally means that you have had too much. Then dry yourself rapidly, using two towels, the first to take off the greater part of the moisture, reserving the second to dry yourself with thoroughly. Just as you began undressing from the upper part of the body downwards, so dry and dress in the inverse order, rubbing the feet and legs and putting on the stockings and nether garments first. After that, if you are feeling chilly, have a hot drink and some biscuits or other light food.

Of all forms of baths there is none so refreshing 
as Turkish baths. The hot air which produces the perspiration also causes it to Turkish evaporate. The sweat-ducts are Baths. cleansed from within as well as from without by means of the profuse perspiration, and the relief to the system is very great.

The patients who benefit most are those suffering from kidney trouble or rheumatism. In the latter case the complaint is due to the presence of excessive waste matter in the tissues; in the former to the fact that one of the outlets is more or less deranged. Free sweating is of untold advantage in both, as it enables the skin to do double duty and help to eliminate the poisonous material.

Of late there has been a tendency to treat common colds and influenza by means of these baths, but in many cases they only increase the catarrh, instead of relieving it. Considering the infectious nature of colds of all sorts too, it is hardly fair to other people to contaminate the air in the bathing-rooms.

People with weak hearts, and full-blooded persons with any tendency to apoplexy, should avoid Turkish baths, as they are not suitable in either of these conditions.

The proper way to take them is to devote plenty of time to the process. On entering, stay in the first room, the moderately hot one, until all feeling of oppression has passed off. Then move on into the second, the hot room as it is called. The third one, called the oven, should 
never be used, as the heat is too intense to be safe.

It is best to be content with a mild perspiration at first, and to stay in too short a time rather than too long. People are apt to think that the more they perspire the better they will be. But that is not the case, and, what is more, there is an element of danger in prolonging the process. So much liquid may be abstracted from the system that the impure matter circulating in the blood becomes too concentrated, and instead of being thrown off may be deposited in some muscle or joint, giving rise to an attack of rheumatism. In this way the very mischief is precipitated that we are anxious to avoid. Taken quietly and with discrimination, Turkish baths are one of the greatest boons to suffering humanity.

One of the most important details is the rest afterwards. This should never be less than half an hour, and an hour or more is preferable when it can be managed. The whole system needs this period of rest in order to get back to its ordinary routine, and without it much of the benefit of the bath is lost.

Once a week is quite enough, and in many cases once every two or three weeks is sufficient to keep the system active and healthy.

One other point should be kept in mind. Seeing that so much liquid is lost in the form of perspiration during the process, it is advisable to sip water freely, both during the process and after it.

If these precautions are observed these baths will prove beneficial to mind and body alike, 
eliminating the impurities, improving appetite and digestion, and restoring the sense of vigour and well-being.

In these ways both Turkish and plain hot water baths are of the greatest service in preventing the onset of neurasthenia and its successor, breakdowns. The time spent in taking them will be repaid a hundred times in an increased enjoyment of life and powers of work. 


\section{CHAPTER XIV.}

\section{REST.}

THERE are more tired people in the world to-day than ever before. Nervous exhaustion is taking the place of the old-fashioned stomach-aches and coughs and colds as the prevailing complaint of the times.

There is a spirit of unrest which is having a bad effect on many nervous systems. The air is dark with threatened strikes, wars and Unrest. rumours of wars, and the clash of conflicting parties. The sense of impending calamity fills the minds of many nervous people with anxious forebodings. Probably things are not much worse, if any, than they have often been in previous times, but news is transmitted to and from all parts of the world with a swiftness that would have seemed incredible even a few decades ago. We hear of things that are happening, not of things that have happened, and there is a vast difference between the two so far as comfort of mind is concerned.

Town life has become much more wearing since petrol has displaced the horse and made the speed of traffic so vastly greater

Conditions than before. And the noise of

of modern motor drays and buses is exercising life. a bad effect on many people's nerves. They may become so used 
to the row that they do not appear to notice it, but its irritating influence on the nervous system is there all the same.

The ever-increasing stress of competition is making work a strenuous affair. But what is worse is the fact that this stress is, with many persons, invading their hours of leisure. We grudge no man his pleasures, but when the rush for amusement is carried on to the detriment of a body that is already fagged out, it is time to stop and think where it is all going to lead to.

The phrase "day and night, Sunday and week-day" is a significant one. It expresses the need for periodic rest as imposed

Periodic by Nature. Loss of sleep is equally rest. harmful, whether it be due to work or pleasure. And whatever views people may hold in regard to the old-fashioned Sunday, when considered from a religious point of view, there is only one when we look at it from the medical side. Change is rest, as we shall have occasion shortly to emphasise, but the increasing tendency to rush off motoring and golfing on Sundays is not change, for the simple reason that most of the people who indulge in these pursuits are the very ones who motor and golf most days of the week. The old-fashioned Sabbath was no doubt carried to the opposite extreme, but it did at any rate infuse an atmosphere of restfulness, which is lacking in these days.

It is not that we wish to encourage idleness. 
That is a very different thing from rest, which implies cessation from work. There What rest is a form of languor due to want of is. exercise, and we meet with people who are always tired because they lounge about too much. But there are others who are constantly feeling languid because they have not learned how and when to take suitable rest.

Some people are always on the go. They habitually walk beyond their proper pace and rush at their work and their amusements with feverish anxiety. Even when they are playing golf, they hurry after the ball as though they were affraid it would run away from them if they did not catch it up.

To people of this type illness, which is usually regarded as a misfortune, often proves a blessing in disguise. For it has one great advantage, in that it imposes upon the system the muchneeded rest which has been denied it.

We compared the human body to an engine. Yet in one respect this simile falls short. For man is a living being, and it is on this account that he needs something that the engine can do without. The marvellously delicate machinery of his body must have rest. An engine is liable to wear and tear, no matter how well it may be put together; even if it is made of the best metal to be obtained, and constructed as nearly perfectly as possible, there is always bound to be a certain amount of friction and concussion, which will in time lower its quality and impair its efficiency. 
But the machinery of the human system is subject to more than simple wear and tear; for there is, as we have seen already, a chemical process constantly taking place, which produces waste matter that must be drained away every day of our lives.

Yet in spite of this, it is in a vastly better position than the engine, for it possesses at the same time a faculty of self-repair. We cannot take out parts and replace them by spare ones, but we do not need to do so. The most marvellous thing about the human system is the fact that waste and repair go on simultaneously. But in order that this may take place the system must have periodic rest.

The object of rest is not merely to add to man's happiness and enjoyment, to give him time for pleasure. It is to recuperate his object body and mind. If he were to go of rest. on using his muscles without any relaxation they would gradually waste, and after a time would waste rapidly and to a serious extent. If he were to exercise his mind without any respite, the delicate brain-cells would become exhausted, for like the muscles they would have no chance of renewing themselves.

Strong, hardy sailors who have had to undergo a prolonged physical strain, as in the case of shipwreck, have been known to suffer ever afterwards from debility; their hearts and muscles had been over-exerted to such an extent that they were never able to recover themselves. And people 
who have had to go through a long stretch of brain work have lain in a stupor for weeks afterwards, unable to use their minds or even know what was going on around them.

Rest is therefore of all considerations of health the most important, and it demands our closest attention. Particularly so because it is those who need it most who find the greatest difficulty in obtaining it. Active-minded people abhor rest ; to their minds it savours of " doing nothing." They do not understand that it is a positive mode of treatment, and that a definite process of repair and building up is going on all the time in the brain-cells and the various tissues of the body.

The question of rest is simple enough in the case of animals and human beings of a low order. The yokel if he feels inclined for a sleep lies down and takes it just as the dumb creatures do. And many a man of education and refinement has envied the tramp his siesta in the roadside ditch. He would give anything to be able to get a rest like that whenever he wanted it. His delicatelybalanced nervous system needs repose far more than that of the tramp or the peasant. Yet, instead of submitting to lie dormant, it is his nervous system which keeps him awake. It is like a fractious child, which will neither go to sleep nor allow its parents to get their rest.

It is a matter of the utmost consequence, therefore, to consider in what way rest can most easily be obtained both for body and mind.

Bodily rest can only be got by having the 
muscles completely relaxed. The ordinary sitting position in a chair is not sufficient, Bodily as the lower extremities are still rest. more or less rigid. The chair should be an easy one, with an extension or a footstool to support the lower limbs just a trifle below the level of the body. A better rest can be had, however, by lying full length on a couch or bed with the arms and legs sprawling in the manner adopted by the tramp when he takes a sleep by the wayside. This attitude assures ease if not elegance. And it does more than relax the limbs, for it gives repose to the heart as well. When the body is in this position the heart beats more slowly than when we are standing, walking, or even sitting.

When we consider that from the moment of birth to that of death this organ is working incessantly, it is evident that it needs rest more than any other muscle in the body. Suppose a hard-working man takes a quarter of an hour's loll in the middle of each day; multiply this by 365 and again by the number of his adult years, and you will have some idea as to the amount of rest his heart has had by the time he has reached middle age.

This position of ease and relaxation has a beneficial effect on the mind also. When we are thinking hard we instinctively contract our muscles. The face of the thinker is always associated with a rigid cast of countenance and a furrow between the brows. Conversely, when our muscles are more or less stiffened the mind 
tends to be concentrated at the same time. Relax the muscles, and the mind also tends to relax.

There is no more efficacious restorative to a tired body than a hot bath, as hot as it can be borne, in fact. It should be fairly deep too, so that the whole body is immersed. Ten minutes or so of this acts marvellously as a refreshing tonic to body and mind alike, especially if followed by a rest in the horizontal position.

Rest for the wearied mind is of even greater importance than for the body, for a tired brain is apt to keep the latter on the rack.

Rest of Every evening thousands of men mind. and women reach home too tired to think and too tired to stop thinking, especially on the very subject which should be strictly left alone, viz. their daily work.

It is not unnatural that they should feel tired. Yet they do not always look at it in this light.

One Sunday evening a parson was sitting by his fireside with a book in his hand which he was vainly trying to read. Time after time he had taken it up, only to put it on one side again after scanning a few lines. He had a look of utter weariness and dejection, and every now and then would start out of his chair and pace restlessly up and down. It was not the first time he had gone through this experience, and he was not the only one of his kind who at that very hour and in a precisely similar manner was having a bad time of it.

Now what was it that was troubling him? In the first place he was tired. That was not to be 
wondered at, seeing that he had conducted three services in the course of the day. Most persons from the navvy to the king feel tired when their day's work is finished, but this does not worry them. There is no more delightful sensation than that of real fatigue.

What chiefly troubled him was the fact that although the book he was trying to read was one dealing with spiritual matters, he was not only unable to give his mind to it, but could not even arouse any interest in the subject. He did not see that it was the most natural thing in the world that this should be so. If a surgeon were to perform three operations in one day, I am quite sure that he would wish to talk or think about anything except surgery. And if a pianist gave three recitals in the day, I believe that the last subject which would interest him would be music. His faculty for it, like the surgeon's for his own art, would be exhausted for the time being. Why then should the parson who had thrown all his spiritual energies into his Sunday's work be surprised to find that his active interest in such matters was in abeyance? His faculties had been confined to a certain groove all day, and refused to work any longer on those lines.

That parson was only a type, if a pronounced one, of many other people, business men, lawyers, doctors, stockbrokers and any other you can mention, who cannot make out how it is that if they think of their work in the evenings they only worry over it. Yet it forces itself upon their notice, and they cannot shake it off. They seek 
rest and find none because they seek it in the wrong way. They try to sit still and think of nothing, and that is the most difficult thing on earth for any intelligent human being to attempt.

We can arrest the movements of the body, but it is infinitely more difficult to stop the workings of the mind. The engine is going at full speed, and we are unable to pull it up. But we can do something equally efficacious, we can switch it on to a different line.

We can give it change. And change is rest. There is nothing more wearying to a mind that is tired and yet strung up than for

Change is any man or woman to sit gazing rest. moodily at the fire, fretting their nervous systems with the worries that should have been left behind. Recreation is as indispensable to health as food itself.

A fascinating novel, a pleasant game or an absorbing hobby will afford the wearied brain its much-needed relaxation.

And when, in one or other of these ways, the mind has been enabled to settle down into a quieter groove, it will be in a vastly better condition to secure the ideal form of rest, nature's sweet restorer, sleep.

So important are these considerations, sleep, recreation and a kindred one, holidays, that they deserve more than a passing reference. In the next few chapters, therefore, we shall describe them more fully. 


\section{CHAPTER XV.}

\section{SLEEP.}

THE ideal form of rest for body and mind is sleep, for during it the muscles are completely relaxed, the heart beats quietly, the functions of the various organs are suspended to a very large degree, and the brain is in oblivion.

This question is one of paramount importance. The individual who neglects to secure the requisite amount of sleep is committing a crime against himself, for which he will have to pay the penalty sooner or later. The experience of centuries has proved that the average man or woman needs eight hours of it daily, and that means that they ought to be in bed for eight and a half hours.

It is not sufficient that these eight hours should be taken at any time of the day or night that happens to be convenient. The old Beauty idea of "beauty sleep" is perfectly sleep. correct, for there is no rest equal to that obtained during the first part of the night, and no amount of lying in bed in the morning can make up for the loss of it.

Ask anyone who has to work at night, nurses, doctors or workmen on night shift, and they will tell you without any hesitation that such work takes twice as much out of them as a corresponding 
amount by day. They will also declare, if you inquire further, that the sleep they get in the daytime is not half so refreshing as that obtained during the night.

Human strength ebbs and flows with the regularity of the tides, with the difference that the rise and fall occurs once instead of twice in the twenty-four hours. The system is at its best from about six in the morning until the evening. It is at its worst from about eleven at night until four in the morning, and during those hours, if people are awake, either at work or at play, and even if they have had abundance of sleep during the course of the day, the heart tends to flag, and all the powers and faculties are lowered. It is on that account that people who have to sit up all night begin to feel chilly and tired in the dead of night, even though the room itself may be quite warm. They feel cold and uncomfortable, simply because their whole systems are depressed. It is for the same reason that people who are ill are almost always worse during these hours.

To sit up night after night, even with plenty of rest in the daytime, is wearing to the system. To do it without that daily rest would speedily cause a collapse And people who habitually sit up later than they should do, not going to bed until midnight or after, are in danger of bringing about the same catastrophe, only in a slower manner. There is a measure of excitement about these late hours which makes them alluring. Many people say that they can work or write more easily or play cards with greater zest then 
than at any other time, but it is a false form of stimulant, for which the system has to pay a heavy price later on.

Regular and early hours are essential to health, and the neglect of them is often the means of starting a breakdown, or bringing Remedies for it to a head. Many cases of sleeplessness. insomnia are due to a want of punctuality in this respect. And of all the tortures with which mankind can be afflicted there is none worse than insomnia, and none that so surely undermines the nervous system. One of the most vital points in the prevention of breakdowns is to consider the different ways in which sleep can be obtainedand to carry them out.

To emphasise what we have just said, punctuality in going to bed is the most important point of all. The brain, like the digestion, has a Punctuality marked tendency to get into in going habits, either bad or good. And if to bed. anyone goes to bed at different times, later on some evenings than others, the brain is liable to select the latter hour as the one for falling asleep. This means that even on the nights when people go to bed in good time they cannot get to sleep for the next hour or two. If they would stick to the one hour regularly, the brain would soon learn to do the same.

Dozing in front of the fire in the evenings is responsible for many bad nights. The mind gets into a half-awake, half-sleepy state, which hinders it from obtaining sound slumber when 
bedtime comes. Even if people are tired and sleepy at, say, nine o'clock, it is better for them to read or play a game or move about in order to avoid falling into a doze.

A brisk walk of ten minutes or so before retiring is often found to be one of the best sleep-producers. Or if the weather be too inclement, a few physical exercises will have the same effect.

Late or heavy suppers are a common cause of insomnia, especially that form of it in which people fall into a heavy sleep, only

Avoid late to awake with a start an hour or suppers. two later and find themselves unable to drop off again until early morning perhaps.

Digestion comes almost to a dead stop during sleep, so that sufficient time should be allowed for the last meal to be disposed of before the hour for retiring. This interval should be two hours at least, which means that half-past eight is, as a rule, late enough for the evening meal. In any case, the food which is taken then ought to be of a light nature, and not include pork, cold meat, or any other article of diet which is slow of digestion. Coffee and strong tea, especially Indian tea, are unsuitable at this hour, as they tend to cause sleeplessness of themselves. Cocoa, made with water, is a much better beverage for use with the evening meal or after it.

Sometimes, however, too long an interval between the last meal and bedtime will prevent sleep, as in the case of those who take high tea at half-past six, or dinner at seven or thereabouts. 
Under these circumstances light refreshments, in the shape of a few biscuits with a light drink of some sort, will assist sleep.

For those who still, in spite of attention to these points, suffer from insomnia, the following hints will be of service.

The bed should be neither too soft nor too hard. If the former, as when feather beds are used, people are apt to fall into a deep

The bed sleep and wake up later feeling half and bedding. smothered. If too hard, the body cannot rest properly. The bedclothes should not be too heavy. An eiderdown quilt is worth several blankets for warmth. If means will not permit of this luxury, two or three sheets of brown paper will answer the same purpose, affording the maximum of warmth with the minimum of weight. The personal clothing, too, should be warm but not heavy, and above all the feet must not be allowed to get cold. The use of night socks will often cure insomnia, which has proved stubborn to all other modes of treatment.

The room should be well ventilated. This is of the utmost importance, and an additional benefit can be obtained by pulling

Ventilation. the bed away from the wall, if only for a few inches, to allow of a free circulation of air all round.

An excellent plan is to sip hot water at bedtime, not too much of it, but as hot as it can be taken. It is not advisable to put spirits Sip into it, as in that case the dose has hot water. to be increased before long in order to maintain the good effect. A 
hot bath, or putting the feet into hot water, is of great use in many cases.

On lying down it is a good plan to take long, deep, slow breaths for five or ten minutes. At the same time relax the eyes, in

Simulate the same way as in gazing at the sleep. distant horizon or into space, of course keeping the eyelids closed. These two points simulate sleep to a certain extent, and are a valuable means of obtaining it.

Reading in bed is not a good habit, as many persons have found that once they have begun the custom they cannot get to

Reading sleep without it. At the same time, in bed. if anyone has been lying awake for hours it is better to turn up the light and read a book than to lie awake in the dark, thinking and worrying of one thing after another. There is no time when life looms so hopeless and forbidding as it does when you cannot sleep. A better plan, however, is to walk about the room for a few minutes, or to sit up in bed and keep the eyes open as long as possible without blinking. It happens not uncommonly that after doing this people fall asleep as soon as they lie down again.

The aimless wandering of the mind from one subject to another and back again may be prevented by repeating a piece of poetry to oneself. Needless to say, it must be something with which we are thoroughly acquainted, otherwise the effort to remember what is coming next will of itself prove a barrier to sleep. 
The best remedy of all is to spend a whole day in the open air. This will often break the sleepless habit, and

Fresh air once a good night's rest has as a soporific. been obtained others will be likely to follow.

There is one other hint which sounds like an old wife's tale. We do not pretend to be able to explain it, but experience has proved its efficacy in many instances. People have found that they can sleep better with the head pointing to the north than in any other position. Every method, however simple or inexplicable, is worth a trial, for there is no condition so distressing as insomnia, or so likely to lead to the much-dreaded neurasthenia.

People often complain that they cannot sleep well in the summer-time. This is owing to the fact of the mornings being light at such an early hour. This can be remedied with the best results to the whole system by the plan of having dark green blinds fitted inside the windows.

Those who, through some illness or infirmity, cannot take exercise, will find the greatest benefit from massage. If skilled

Massage. massage cannot be obtained, gentle rubbing of the limb will fulfil the same useful purpose. 


\section{CHAPTER XVI.}

HOLIDAYS.

THE greatest mistake than can be made is to wait for an annual holiday in the expectation that it is. going to exonerate us from consequences of eleven months or more of sinning against the rules of health. Everyone, men and women alike, should secure a holiday if only for an hour or so every day of their lives, in the shape of some congenial. change of thought or occupation.

Yet the annual holiday has a place of its own in our well being. It takes us away from our ordinary associations, and brings

Value of us into contact with fresh scenery the annual and new faces, which mean new holiday. personalities. It invigorates our bodies and tones up our minds, broadening them and furnishing them with new ideas, so that both from the physical and mental standpoints it is a valuable aid to health.

It has a direct bearing on the subject of breakdowns, for change of scene is a potent means of getting a man's mind out of the monotonous groove which is so wearing to his nervous system. It has an additional advantage in that it often happens that after a holiday he is apt to keep himself in contact with the fresh air and exercise, and recreation also, which he found so beneficial 
when he was away from home. In the incipient stages of breakdown, too, a complete change is one of the necessary items in treatment.

Seeing, therefore, how important it is and what it means to so many people, it is well worth while to consider how the time and money involved may be expended to the best advantage.

The usual plan is to fix on a spot because we have heard it spoken of as a " nice place to go to," engage rooms by letter and set off, hoping for the best. Little wonder that the holiday often turns out a disappointment.

A family was returning from a visit to the seaside, to which the various members, parents and children alike, had looked forward with the greatest zest. The mother was tired out, the father seemed worried, and the children were jaded and spiritless. They had been unfortunate in their choice of a place, the lodgings had been uncomfortable, and the holiday had proved a failure. Yet with a little foresight it might have been entirely different.

It is always advisable that one of the older members of the family, preferably the mother, should see the locality and the apartments before hand. We cannot expect the proprietress of the apartments or the hotel to point out for our benefit that the bedrooms are musty and badly ventilated, the sheets damp, and the sanitary arrangements defective. We must go and investigate these things for ourselves.

The question as to where to go is one that needs 
careful consideration. The fact that it suited someone else is no reason why it Where to should be adapted to our requirego. ments. I once heard two men discussing this question, and one was advising the other to go to a certain place in the Highlands. $\mathrm{He}$ described it in glowing colours, and made it perfectly plain to the other man that if he went anywhere else he was an incompetent idiot. It was a village at the bottom of a deep valley, surrounded on all sides by lofty mountains.

"What do you do with yourself if the weather is wet?" the second man asked.

"Well, of course you have to stay indoors."

"And what do you do when it is fine?"

"Oh, you climb the mountains."

"Well, seeing that my wife suffers from a weak heart, and cannot climb an ordinary hill, I think we shall go somewhere else," which he very wisely did. It is not much use going to a place if you have either to forego the pleasures of the holiday or run the risk of injuring your health.

People who suffer from asthma are often worse at the seaside, and should always take this into consideration. Those liable to bronchial attacks should be wary as to visiting the East Coast. They will derive more benefit from the softer atmosphere of the South or West.

It is a mistaken idea to suppose that people who are run down will get the most good from going to a bracing climate. . Often it has the effect of 
making them irritable and restless, and their nerves do better in a more relaxing place.

A fortnight on a farm always sounds attractive, but in reality it often turns out the very opposite. The accommodation is apt to be of a primitive order, and the cooking by no means up to the mark, while it is not uncommon to find that none of the bedroom windows will open. So much, too, depends upon the weather, and if it happens to be wet, the holiday is likely to be devoid of pleasure, and detrimental to health at the same time. Rheumatic people should avoid farmhouses, as the atmosphere is often damp, especially in the evenings. Even if the weather is fine, there is a danger in the dew which rises from the fields at sunset. If it is wet, the consequences are apt to be serious. A seaside place with a light, sandy soil is better adapted to such persons.

In these days of quick and cheap travel no paper on holidays is complete without a reference to the problem of continental trips.

Continental These are undoubtedly a source of trips. interest, but not necessarily of health. It may be a delight to see fresh places and experience new national customs and a totally different diet, but in many cases these advantages are obtained at the expense of bodily health. People who are run down rarely get any benefit from them. Even if they have the sense to make for one place and stay there or use it as a centre, the long railway journey tires them to such an extent that they cannot enjoy 
their holiday properly. Usually a visit to some home resort is of infinitely greater value.

As a rule, however, a continental trip means one of the advertised tours, in which a maximum of travelling and sight-seeing is carried out in a minimum of time. People who are strong enough to undertake such a task do not come under the category of health-seekers.

When the journey, either home or foreign, includes a sea-trip, it is well to take only light food for a day or two previously, if you are subject to mal de mer, and also to take a good aperient the day before starting. These precautions will often serve to avoid the biliousness which so frequently spoils the first few days of the holiday.

In making preparations for a holiday it is necessary to be ready for all sorts of weather. The day may be tropical when we Preparations. start, and like winter the next day, and it is both uncomfortable and dangerous to have brought nothing but light summer clothing. There is an old superstition that people do not catch cold by the sea. This is a huge mistake, as they are just as liable to do so as at home, often more so in fact, as home comforts are missing. It is a pitiable sight to see numbers of people wandering about a seaside resort on a damp, chilly day, looking cold and miserable, simply because they think it their duty to dress in flannels while they are on a holiday.

That phrase " on a holiday" covers a multitude of sins. People seem to think that they can 
dispense with all the precautions they would find necessary at home, and that they will escape the consequences of running needless risks because they happen to be at the seaside or in the country.

The result is that many people complain that they feel tired and headachy when they are on a holiday, and that much of their pleasure is spoiled in consequence. They attribute it to the fact of the air being too strong for them, or else that it is the reaction from previous overwork. It is neither one nor the other, but is due to something quite different.

For one thing, most people eat too much when they are away, a great deal more than they would dare to take at home. Often, too,

Diet on a they indulge in things which they holiday. know to disagree with them in an ordinary way. The consequence is that they become dyspeptic, and their livers get out of order. That is why they have headaches and get tired so easily. If they could take less rather than more, and eschew all those things which do not suit them, the value of the holiday would be considerably enhanced. In the case of men, smoking to an excess they would never dream of at home has a similar effect in producing a feeiing of lassitude.

The amount of exercise has a pronounced influence on the good of a holiday. People who have been overworked or

Exercise. ill, or have neglected to take regular exercise at home, should be extremely careful as to exertion when on a 
vacation, particularly during the first few days. A man who had saved up for a long time to have a fortnight among the mountains did so much climbing on the first day that he was knocked up for the remainder of his stay. Many others, without going to extremes such as this, feel languid all the time from the same cause. They try to make up for lost time at home by doing as much as possible in the weeks at their disposal, and think it a crime to miss any opportunity of getting about. They walk more in a day than they do in a week at home, and are surprised to. find that instead of feeling braced up they are listless and tired out.

Unwonted forms of exercise, too, such as many persons indulge in when away from home, are responsible for more than the spoiling of their enjoyment. For example, it is not necessary for them to bathe simply because they are at the seaside and everybody else is having a dip. Numbers of people in good health do not feel well for the rest of the day after a bathe, but in other cases the results may be more serious. Those who are run down, or broken down, or are recovering from an illness, had better avoid entering the water. Otherwise they run the risk of bringing about a recurrence of their malady.

Exercise of all sorts is an admirable thing, but like many other good things in this world it has to be used with discretion. For alongside it there is the companion virtue rest, and this aspect of a holiday has always to be kept well to the fore, especially in the case of those who are feeling 
jaded or depressed, restless, nervous or irritable, or present any sign of incipient neurasthenia or breakdown.

For people of this type a restful holiday is essential above all things. But this does not mean that they are to go to some

The restful quiet spot with no company except holiday. their own thoughts. It needs a peculiar temperament, such as few of us possess, to spend a fortnight lying under a hedge or on the sands in some secluded place, with hardly a soul to speak to. It is all very well in theory, but in practice it usually amounts to the very opposite. The body may be rested, but the mind is apt to be kept on the go. Black care rides behind the horseman, and a man's worries too often accompany him and refuse to be driven away, unless he has some amusement or interest to divert his thoughts.

If people happen to be ardent lovers of Nature, they may find diversion in some place noted for its scenery. Unfortunately, however, the neurasthenic is easily bored, and no matter how beautiful his surroundings may be, he should take care to furnish himself beforehand with plenty of literature suited to his needs. The local library is often interesting when regarded from the point of view of the antique, but it is often hopeless as a means of securing anything worth reading.

In many cases people who run down need something of a lighter, we might say a more frivolous nature. Their taste for scenery, like 
many of their other faculties, is tired out for the time being. Taken all round, the best place for the neurasthenic is a lively seaside resort, where he can sit about and amuse himself with watching the doings of the people around him. Everything in this world has a place, and a troop of nigger minstrels or a Punch and Judy show may afford rest and relaxation to a wearied mind when mountain scenery has failed to do so.

In either case one thing is essential. The scenery or the amusements must be obtained with a minimum amount of fatigue. On this account it is necessary to select a place mild enough to permit of sitting out of doors. That is why in the great majority of cases the neurasthenic gets on much better in a warm, if relaxing, climate.

One other point we must emphasise particularly. Many visitors, whether they are run down or in good health, suffer from headaches

Tired eyes. when on a holiday simply because of tired eyes. They want to enjoy the full benefit of the air, and are also ambitious to return home sunburnt, so walk about without any proper shade to the eyes. They succeed in getting tanned, but much of the pleasure of their vacation is spoiled owing to a constant feeling of ache and oppression in the head. A wide hatbrim or a pair of smoked glasses will avert this, and add to their enjoyment in proportion as they do so.

For the same reason a good rest in a shady room in the middle of the day is of the greatest value. It rests not only the eyes but everything 
else as well. People regret the waste of a single minute when they are taking a hard-earned holiday, and often ruin the good of it by staying out of doors until they are too tired to enjoy themselves. An hour's rest in the house after the midday meal will be found to make their holiday worth twice as much as it would be otherwise.

It is always a pity to spoil the good effect of a holiday by returning home at the last possible minute, late at night it may be. Returning Better lose half a day of the vacahome. tion than get up next morning to resume work tired out and utterly unfit for it. For this will rob the holiday of those pleasant recollections which are one of its greatest boons. 


\section{CHAPTER XVII.}

RECREATION. HOBBIES

RECREATION may be divided into games, reading and hobbies. Games occupy a useful part in daily life. Indoor ones form a

Games. pleasant way of passing the time, and helping to take the mind off work and everything else that tends to cause worry or fatigue.

Outdoor ones tempt people to fresh air and exercise, and thus constitute a valuable aid to health. And games of all sorts do one thing, they teach people to take a beating in good part. By games we mean of course the playing, not the watching of them. One game even badly played is worth fifty hours of looking on while others take part, even if they are experts and play vastly better than we could ever do.

Yet games necessitate having someone to play with, and there are many times in our lives when we cannot have anyone else

Hobbies. to take a part. That is the great advantage of hobbies, they can be enjoyed in solitude.

Not that we have any wish to drive people to solitude, for there is nothing worse than being alone too much. Solitary people are very apt to become too introspective, and that is always a 
bad thing for their nervous systems. If people avoid the society of their fellow-men they acquire an undue sense of their own importance, and their own affairs loom too largely in their thoughts. Furthermore, they are liable to become depressed, and to develop that mixture of conceit and diffidence which is of all things most objectionable.

It is because solitude is inevitable that we are anxious to lay stress on those things which will effectually prevent that morbid introspection and make life brighter and happier. And hobbies fulfil both these requirements. There are thousands of people who are doomed to live in lodgings. They have no one at hand to join them in a game, and unless they have some congenial occupation wherewith to occupy their minds, life becomes a poor, dull affair.

It often happens, too, that those who have the privileges of family life have to depend on themselves for their own amusement at Hobbies and times. The other people in the home life. house may be busy or disinclined to take part in any game. Besides that, games are apt to pall in time; you cannot carry them on indefinitely. Then it is that a hobby becomes a priceless boon. It does more than enliven solitude, it makes all the difference to home-life also.

A man returned home after a hard day at business, and after he had had his meal sat down and spent the evening gazing with a bored, tired countenance into the fire, a cheerful spectacle for his poor wife, who had also had a worrying day, 
and would have been glad of a little brightness. The boys and girls had even to be sent out of the room, as their talking made father's head ache.

As he sat there his one thought was of his work. It was all he had to think about, for he had never cultivated any pursuits or broadened his interests in any way. And running the mind in one groove is, like singing on one note, a tiring occupation. That man was always tired, body and soul. Of late, too, he had had another worry, for he had found himself becoming more nervous and irritable, and with less confidence in his own powers. The dread had come upon him that he was going to break down. And as he thought of his wife and family, who would be left insufficiently provided for, it nearly broke his heart.

Twelve months later if you had gone to that same house you would have seen the table littered with prints and negatives. Blessed be untidiness, of that sort at any rate ; it generally means, like the dirt on a boy's face, that someone is happy. There were no tired looks now, and no sending the young people out of the room Instead, everyone was cheerful, everyone talking at once, and as for father, you would not have known him. Even the children did not know what was coming over him, he was getting so jolly. His friends, too, and he had more of them of late than he used to have, were glad to meet him, instead of fighting shy of him as an old bore like they used to do.

The secret of it all was that he had been to a lecture on birds, and the lecturer had described 
the fascination of photographing them in their haunts. He had taken it up, and the result was that he had seen more than birds, for his eyes had been opened to all the beauties of Nature, and he had found the world a very pleasant place to live in after all. The fresh air and exercise which he had enjoyed whilst following his new bent had banished his dyspepsia, his headaches had disappeared, and he had forgotten all about the palpitation and vague pains and discomforts that used to worry the life out of him.

His nervous system had taken a new lease of life. He had lost all his dreads and forebodings, and had regained his old confidence in business matters. The old wearing monotony of life had gone, and his brain was alive and keen with varied interests, for no hobby comes alone, it invariably brings its friends along with it. And the more the merrier.

This welcome change in his manner of spending his evenings, the change from wearisome brooding to congenial pastime, had given to his mind the repose it had stood so badly in need of, and for want of which it had been slowly but surely drifting towards a breakdown. For the latter is due, as we have already seen, to a gradual disorganisation of the various functions of the body undermining the nervous system. And a hobby such as this, combining indoor and outdoor pursuits, does more than relieve the tedium of a tired brain, it invigorates every organ and tissue in the body.

And they not only act as a direct preventive of 
breakdowns themselves, but they are an invaluable aid to other forms of treatment.

Hobbies If a lethargic person is ordered to in the take exercise, it is a constant treatment of difficulty to keep him up to it, breakdowns. unless he has some other inducement. Get him to take up some outdoor pursuit, such as gardening or natural history in one or other of its multifarious phases, and he will have exercise in abundance without knowing that he is taking it. Numbers of men would be vastly better in health, too, if they had more exercise after reaching home, especially on winter evenings, instead of sitting by the fire until bedtime. If told to take up physical drill, they may go on with it for a time, but will almost certainly get tired of these duty exercises after a while. Persuade them to take up wood carving or carpentry, and they will get all that they need and a large measure of enjoyment at the same time.

Many a case of gout, dyspepsia, sluggish liver and such-like ailments in stout, plethoric persons can be cured by this means more effectually than by any other.

Or it may be that patients are ordered rest, because of some overstrain, or a weakness in some particular organ, as the lungs or heart. It is difficult enough to secure this rest in the case of a woman, but in that of a man it is wellnigh impossible. There is no more restless being than a man who is either confined to the house or unable to walk far. He gets tired of reading and playing "Patience," and the result is that in most 
instances he moons about aimlessly, a nuisance to himself and to those around him. Once let him take up some hobby which will interest him, and the case becomes entirely different. He can take his camera and photograph places or people, near at hand or farther away according to his powers of walking, and can find ample occupation in the evenings or on wet days, developing, printing and arranging the pictures he has taken.

Or he can take his specimen case and spend whole days quietly hunting for wild flowers, birds' eggs, or anything else he is inclined for, and obtain a vast amount of pleasure afterwards in setting out his treasures. Or he can do a bit of gardening, heavy or light according to his capabilities, and if he has a greenhouse he can fill up his time profitably when the state of the weather does not permit of outside work.

Hobbies have ceased to be regarded simply as a means of putting in time, and have come to occupy an important part in medical treatment. Consumptive sanatoria, for instance, present a very different appearance now from what they did some years ago. At that time the visitor was met with the pitiable spectacle of a melancholy array of dispirited patients, lying about in all stages of dejection. Now he sees men and women engaged in gardening and other outdoor pursuits, looking as if they were thoroughly enjoying themselves, which is just what they are doing.

The same benefit from such pursuits is found in all cases where fresh air is required, as in anæmia, neurasthenia, etc. An outdoor hobby 
secures the fresh air, and supplies the best of tonics for nervous systems. And when breathing exercises are ordered at the same time, the easiest way to ensure their being carried out is to induce the patient to learn singing, which is the best and most agreeable form in which they can be applied.

As to the stage of convalescence from any illness, any medical man will testify that people who have hobbies get well very much sooner than those who have not. And in this case, as in all those of people whose lives and movements are limited owing to some physical weakness, if they have no such pursuits to brighten their lives, the incessant worrying and brooding are very liable to result in neurasthenia, which is the half-way house to breakdowns.

And for those of my readers who still retain the priceless gift of health, and wish to retain it, a hobby is better than all the riches in the world. It is independent of riches, too, for anyone can cultivate it, the poor as easily as the wealthy. More easily, in fact, for the more difficult a thing is to acquire the more we enjoy it when we have secured it. The man or woman who can fill their house with treasures of art and literature simply by signing a cheque rarely appreciate what they have got.

When making a start take up anything, it does not matter what. One hobby leads to another, and it leads to something else,

Choice of a which is one of the most potent aids hobby. to health. For no sooner has anyone begun a fresh pursuit than 
they meet with someone who is interested in the same subject. A hobby has been the means of the beginning of many a lifelong friendship. And a congenial friendship is the best remedy for the headaches and heartaches and soulaches with which lonely people are so often afflicted, to the detriment of their nervous systems.

For those who wish to cultivate some hobby to act as an evening pastime, and give the mind its needed rest, it is important to choose one that is a contrast to their daily occupation. If they work with their brains all day, they should take up some pursuit that involves manual exercise. If they are working all day with their hands, they are better advised to fix on one that makes a call upon the mind, without much physical exertion. They may start a course of reading, for instance.

Now reading implies either amusement or instruction, or the two combined, as in the case of history or travel. In these days both these subjects are presented in a form that is not only an education, but also a welcome relaxation to the tired brain. It is a relief sometimes to have our minds carried back to the ages, and realise that the troubles which beset us are just the same as those from which people have suffered right down through the centuries.

We can have all the pleasures of travel without the disadvantages-gazing at the ruins of some Indian temple without being suffocated by the heat, or wandering in tropical forests without being bitten to death by mosquitoes and running the risk of malaria. 
Or if the eyes be too tired for reading, there are hosts of other pursuits which will render agreeable diversion to the mind. A husband and wife who spend their evenings, the one with music or some interesting hobby, and the other with her fancy work or French painting, are more likely to be " happy though married," than if they sit in their chairs to a growling accompaniment of the day's worries and a querulous account of the servants' doings.

Life without a hobby is like a dinner without salt; it may be inoffensive, but there is a sad lack of relish about it. 


\section{CHAPTER XVIII.}

WORK.

WoRk is the natural heritage of mankind. "Man goeth forth unto his work and to his labour until the evening." He does so in order to get the means of livelihood. Yet even those who inherit sufficient to make them independent must work also. They may not have to work in order to live, but they must of a certainty work in order to live healthily.

A certain statesman, well endowed with this world's goods, has been known to say that even when he is out of office and on a

Necessity holiday, he finds it necessary to his

for work. personal comfort to study hard for at least two or three hours each day, otherwise his nerves and his heart begin to trouble him. And while making due allowance for patriotism and sense of duty, there is no doubt that many men who do not need to work for a living take up work of some sort or other, politics, the army, or whatever else takes their fancy, because they feel vastly better for having something definite to do.

Work affords systematic exercise for the mind, and a mind to be healthy needs exercise as much as the body does. Why is it, then,

Work that if work is indispensable to our as mental bodily welfare from a health point of exercise. view we all look forward so eagerly to the time when we can retire and 
leave it behind us ? Yet that seems to be the goal towards which we are most of us striving. And it is an aimless one, unless a man has some pursuit by means of which he can use and enjoy his years of leisure, some absorbing hobby or public work of one sort or other. It is the man who has applied himself so closely to his business or profession as to have deadened his interest in other matters, who finds retirement such a deadly dull affair.

It is often said that a man does his best work before he is forty. The cry is for young men in every branch of employment, and

How to those who have reached middle age work and be stand a poor chance if they are so healthy. unfortunate as to lose their situations. Yet their experience ought to make them more useful and indispensable than at any previous stage in their career. A man of fifty-five complained to me some years ago that he was being put on the shelf on account of his age. "Yet I am better fitted to do my work than I have ever been," he said.

It is quite true that he was better fitted for it from the point of view of experience and judgment. Yet he was a confirmed dyspeptic, and was always taking cold, necessitating frequent absences from his work, which was a responsible one. And it is just on this very account that there is a demand for younger and stronger men to-day. Employers prefer a man who is warranted to turn up when he is wanted, rather than a more experienced one who is liable to be at home indisposed at the 
very time when his services are most urgently needed. They say quite rightly, "We cannot afford to have a man who is in danger of breaking down."

Most of the breakdowns that we meet with are put down to work or overwork. It is, therefore, looking at the matter from the personal point of view, a burning question as to how work can be carried out without bringing in its train this much-dreaded climax. In other words, "How to work and be healthy."

It is folly to go blindly on, as so many do, hoping for the best, and taking no steps to make sure of it. It is not work, but the conditions under which it is done, that accounts for the loss of health which so often accompanies it. And much of this loss, and most of the breakdowns which occur as a result of it, may be avoided by a careful, practical study of the whole question.

We need to look at it from three points : before, during, and after work.

If a man lies in bed until the last minute dresses in a hurry, perhaps cutting his chin while shaving and losing his shirt stud, Before bolts down his breakfast in the work. fewest possible minutes, and then runs to catch his tram or train, it is not to be wondered at if he returns home in the evening thoroughly fagged out. He has started the day by breaking nearly every rule of health in the course of about three-quarters of an hour, and is surprised and worried because he finds 
that his work takes such a lot out of him. Yet next morning he begins by doing the very same thing over again.

Then he sighs for the time when he will be able to rest on his oars and take life easily, leaving "the beastly business" behind him. And so long as he goes on in the way he is doing, he will sigh for it in vain. He may feel thankful if he is able to go on with his work, and does not find himself laid on one side, broken down in health and spirits.

Try an experiment, some of you who see yourselves in the picture I have just drawn. Get up in good time, and that means going to bed in good time also the night before. Dress and take your breakfast in a leisurely manner, and then either go for a turn in the garden or farther afield if you like, or else have a quiet rest by the fireside, if the weather is inclement. Give yourself plenty of time to get to your place of business, and at the end of the day you will be in a position to decide as to whether it was your work or your way of starting the day which was. to blame.

Of one thing we have little doubt. Even if you do not feel as. well as you might do when you reach home again, you will feel better than you have done for a long time past. But not so well as you may do before long. For there are different ways of going about your work, as well as of preparing for it and getting there.

It is astonishing how many people there are 
who are careful as to ventilation and such-like matters in their own homes, but During work. will put up with all sorts of hygienic Hygiene. defects in their offices. They will sit with their heads or their feet in cold draughts in the winter time and in baking hot rooms in the summer. A strip of wood under the door, or a curtain over it, the removal of a desk to a more convenient position, or the fixing of a sunblind, as the case may be, would make all the difference in the world to their comfort and health. Yet they put up with these inconveniences, and go on taking colds and headaches, just because it is an office or a place of business and not a private house.

Noises in the street outside are a frequent cause of tiredness. Through long custom people fail to hear them, and become unaware of Noises. their existence, but the consequent nervous tension is there all the same. No expenditure in the shape of mechanical contrivances, even if it necessitates some re-building, is too great if it can mitigate this constant sourcc of irritation to the nervous system.

As to the telephone, we are almost afraid to mention it, simply because we have no remedy to suggest. There is no doubt that

Telephone. it has increased the stress and strain of work considerably, not merely by forcing the pace, but also by its direct effect on the nerves of the head.

We are only able to offer one piece of advice, and that, we frar, a poor one. It is this. Do 
not lose your temper if it is not working properly. It may be a source of satisfaction to tell the operator at the Exchange exactly what you think of him and the system in general, but invective is like a boomerang, it often does more damage to the thrower than to anyone else.

One of the common causes of strain is the habit of writing in a bad light, or with the eyes facing the light. Nothing causes the brain

Bad light. more discomfort than a constant glare of light on the face, or trying to read or write in a poor light. And there is no need for it. It must be a poor sort of office where the window, or artificial means of lighting, cannot be so arranged as to illuminate the paper without causing any strain on the eyesight.

Whether headaches be due to this or any other cause, they should never be neglected, especially if they are liable to come on while at work. For repeated headaches, even though they may be but slight, have a wearing effect on the brain and other parts of the nervous system. They may be due to most trivial causes in some cases, which is all the more pity why they should be allowed to persist. A man who was at the head of a large firm once consulted a doctor because he found that his work took it out of him more than before. The medical man noticed that the patient was slightly deaf, though the latter did not seem to be aware of the fact. On examination, the ears were found to be blocked with wax, the removal of which restored the man to his usual state of health and vigour. It had been simply 
the strain of trying to hear what was being said which had produced a constant sense of fatigue.

There is one custom which in these busy times tends to be dying out. It is that of the midday meal rest, the old-fashioned forty Midday rest. winks. "There is no time for it now," people say. But there is time for everything, if we choose to make it. The head of one of the largest firms in this country used to insist on this rest, no matter how urgent the matters might be that needed his attention. He kept a couch in his private office, and each day, as soon as he had had his lunch, he locked the door, and for twenty minutes took a comfortable rest and snooze. And woe betide anyone who disturbed him. It was to this custom that he attributed the fact that he had retained his faculties and vigour to an age at which most of his contrères were dead or broken down.

Some may prefer to have a walk in the fresh air, and if their occupation is a sedentary one and they have been cooped up in an office all the morning, it will probably suit them better than lying down.

It is not uncommon to find cases in which there is over-fatigue because the intervals between the meals is too long, apart from any

Intervals circumstances which interfere with between them. A man gets his breakfast meals. at eight o'clock and his lunch at half-past one it may be. $\mathrm{He}$ objects to eating between meals, so takes nothing for the whole of that time. Now this for most 
people is too long; the system becomes exhausted, and has to do its work without proper nourishment. This means that it has to draw upon the reserve forces, and while this may be done now and then, it cannot be repeated often without depleting them. Many people would find the greatest benefit from a little light refreshment in the course of the morning. They do not need much : a cup of coffee or soup, or a glass of milk and a biscuit, are quite sufficient to keep them going until the luncheon hour.

For the same reason a cup of tea with bread and butter or cake about four o'clock or thereabouts is an excellent thing. And like the morning snack, it provides more than nourishment, for it necessitates a break and a breath of fresh air, which invigorate the nervous system, and often enable a man to reach home fresh and well, when otherwise he would get there jaded and tired.

Sometimes it is the nature of the work which imposes a special strain. Great responsibilities and grave issues may have to be

Nature of met, as in the case of contractors, work. stockbrokers, etc. An enormous degree of nervous tension may have to be concentrated into a few minutes. There is no escaping from it, we know. Yet the man who has consistently looked after his health, not only in the mornings before setting out but at all other times, is in a much more satisfactory state to deal with such emergencies and to bear the strain of them.

Often it is working against time which does the 
harm. Sometimes this rush cannot be helped The journalist, for instance, must Working have his news or his leader ready against time. by a certain hour. The newspaper, like time and tide, cannot wait. Yet at other times it can be helped. A man finds that if he goes on for another hour, instead of going to his lunch or dinner at the proper time, he can finish what there is to do. He may finish his work, to be sure. Often he finishes himself at the same time. It would be to his advantage in the long run, if he left the work and had his meal, and returned to complete his duties afterwards.

This interference with meal-times is a fruitful source of nervous exhaustion and breakdown. The system is deprived of nourishment just when it is most in need of it. Every meal postponed under such circumstances brings the hour of retribution nearer.

Apart from interference with meals, working against time has a bad effect of its own. It is like running for a train. A man who Mental could cover the same distance in effect of the same time without any effort hurry. if there was no train to catch will arrive at the station breathless. The anxiety of getting there in time has caused a mental disturbance, which has affected the heart on its own account. In the same way there are cases of nervous exhaustion and loss of health due entirely to the habit of rushing at correspondence in order to get it off by a certain post. It may have to be done, but the man would be 
better off in the end if he lost the business rather than acquire it at the expense of his health.

There is a peculiar strain connected with work which demands appearing before the public. It is pitiable to reflect how many artistes, Public work. actors, musicians, and others break down in their efforts to give pleasure and diversion to the tired minds of others. The reason lies in the fact of their having to do a certain thing at a certain time, and to do it with an audience. They must give their performance and maintain their highest standard of excellence, when perchance their heads are aching, or they have got a bad cold and are only fit to be in bed. They must be up to time, or they may find their place occupied by another.

For similar reasons the parson is always vastly more liable to breakdowns than the lawyer or doctor. He may get up feeling tired or ill on Sunday morning, but, except at the risk of causing great inconvenience to others, he must put in an appearance in the pulpit.

Yet there is another consideration which enters even more largely into the question. It is that these public appearances often interfere with meal-times and sleep. A performance or a meeting in the evening necessitates a delayed supper and late hours of retiring to rest." The nervous system is at the same time worked up into an excited condition, so that it has its rest and nourishment cut off just when it stands most in need of both.

Much of this may, however, be avoided by 
judicious care. There have been speakers, artistes and other public characters who have been able to continue in harness up to an advanced age. They have achieved this simply by strict attention to the needs of the body. They would fortify themselves with a good meal beforehand; whatever else happened, they would not allow that function to be interfered with. If they could not get food before leaving home, they would arrange for it to be ready for them at the rendezvous. On arriving home again, they would give their nervous systems the best chance by taking a meal and then having a quiet read, with a smoke if they were so inclined, afterwards going to bed as soon as was compatible with their digestions.

Many of these may seem trivial details, yet it is the little things of life which amount to so much; and if these precautions are observed, there are many weary workers in all ranks of life who will find that labour loses much of its drudgery. If everyone were to carry them out, we should see fewer haggard faces and tired eyes than we do at present. One has only to travel in any suburban train to find out how many people there are who go home each evening weary and done up. This is not what life was meant to be. Honest fatigue there will always be, but no one objects to that. It is the jadied despondency on the faces of so many people at the close of their day's work that is contrary to all principles of humanity. It is one thing to be tired; it is a different thing to reach home more dead than alive, and ready to drop.

If people would take more care in preparing 
themselves for their daily duties, and in improving their conditions of work, both for themselves and their employees, we should hear very much less of breakdowns than we do at present.

The way in which people spend their spare time in the evenings is of the greatest importance. It is their opportunity for repairing After work. the wear and tear of the day's work, and of fitting themselves to stand the brunt of that which is to come. The manner in which they spend it depends largely on the nature of the day's proceedings.

If a man has been sitting at a desk all day, he will be all the better for a walk on returning home. It will give him a chance

Exercise or of fresh air, and the exercise will do rest. his cramped legs good. If, however, he is tired in body as well as mind, a rest is what he needs. A man was once suffering in health, and always feeling done up. He rarely had an appetite for his dinner in the evening. It was all due to one thing. He was in the habit of going for an hour's hard walk each evening after returning from business. He did it with the best of motives, being impressed with the value of exercise. He overlooked the fact that he had had as much exercise as he could stand already, as his work not only threw a strain on his thinking powers, but also involved a constant amount of standing or walking throughout the day. When he stopped taking this duty walk-for such it was, it gave him no pleasure, as he was too tired to enjoy it-his health improved by leaps and bounds. 
There are many such persons who would feel vastly better, and have better appetites and digestions, if they took a rest on reaching home, instead of rushing off to golf or for a walk. It would refresh them as much as exercise braces up those who have had too little of it during the day.

As to the recreations with which people seek to restore their lost energies, that too must vary according to the nature of their Amuse- daily avocation. Chess is a ments. splendid game, there is no doubt. Yet anyone who has had a mental strain all day had better choose something that demands less call on their thinking powers. Under such circumstances we confess to a preference for something of a lighter or more frivolous nature. Anyhow, in whatever way people choose to spend their evenings let it be a change, for in that way alone can rest be obtained. The brain worker had better select fiction or some such light form of literature if he is disposed for reading. But there are thousands of people whose work is cut and dried, and does not involve any mental strain, who would improve both their minds and their sense of well-being by taking up some reading or hobby which demands a certain amount of application and study.

The great point after all is to do something, anything rather than nothing. Not that they can do nothing if they try, for it is an impossible feat, as we all know. Yet the trying to do it is the greatest effort a man can make, and tires him out more rapidly than anything else. 


\section{CHAPTER XIX.}

WORRY.

IT is a true saying that worry, not work, kills. People can get through an amazing amount of work if they do it in a quiet and methodical manner.

One morning two men were walking along a road in the direction of a railway station. One of them was going at a steady pace, with a look of contentment about him, as if he were enjoying the walk. The other was hurrying along with quick, nervous steps, occasionally looking at his watch and breaking into a short run, while his strained expression and panting breath formed a marked. contrast to the easy deportment of his friend.

They both caught the train, but while one was. cool and collected and felt invigorated for his work when he reached the terminus, the other was hot and flurried, and this gave him a bad start for the day. Moreover, each of them transacted his business in much the same way as he had walked to the station, one doing it quietly and methodically, while the other spent his time in rushing from one thing to another, taking his lunch in the fewest possible minutes, and constantly worrying himself and everyone else into the bargain.

The singular part of it was that the quiet, steady-going man got through more work in the 
day than his friend did, and years later, when they had reached middle age, was as fit as ever for his business, whereas the other man was broken down by overwork, as he called it.

In the last chapter we considered the question of physical and mental fatigue resulting from work. We purposely omitted the element of worry, which does more harm than all the other conditions of work put together. For worry does more than tire the mind-it demoralises it.

In a certain war two companies of men had to march an equal distance in order to meet at a particular spot. The one arrived in perfect order, and with few signs of exhaustion, although the march had been an arduous one. The other company reached the place utterly done up and disorganised. It was all a question of leadership: the captain of the first company had known his way and kept his men in good order, while the captain of the second company had never been sure of himself, and had harassed his subordinates with a constant succession of orders and counter-orders, until they had hardly known whether they were on their heads or their heels. That was why they arrived looking completely demoralised.

Now worry has precisely the same effect on the mind as a bad leader has upon his men. For the mind is not a vague mystery Worry " somewhere inside the head," as it and the is generally supposed to be. The mind. brain is a matter of tissue and blood, the same as any other part 
of the body. We may not know quite so much about it, but that does not affect the question. The workings of the mind are as definite and practical as the movements of the fingers. The brain cells have, stretching out from them, a number of minute filaments. We know that the tips of these filaments move about and touch their neighbours. And according to the manner in which they move, different trains of thought are set up. The intricate network is constantly changing its form, as the filaments link up together various parts of the brain tissue.

It is, in fact, the counterpart of a telephone system, which has wires and exchanges and call offices extending all over the country. From these offices telephone callers are put into communication with each other, and there is a never-ending linking-up and switching-off taking place, and the harmony of the systems depends on the efficiency of the operators. Fill one of the exchanges with a lot of fussy, ill-trained people, who would lose their heads, and the whole system would be disorganised in a very short time.

Each man possesses his own telephone system inside his head, and the working of it depends entirely on himself. If he fidgets and fumes and gets excited over what he is doing, he worries the brain filaments until they begin to act all ways except the right one. And not only do they fail to carry out their purpose, but the bother and flurry through which they pass tire them out as no amount of steady work could ever. do. Like the men of the second company, they 
get to the end of their day's work fagged and exhausted.

If this goes on long, for days and months and years in succession, the strain becomes too great, and they either refuse to work at all or they get completely out of hand. And, whichever they do, it means that the man who owns them suffers from a breakdown. And it was the worry, not the work, which caused it.

Some people have a born knack of worrying. The mental agony through which they pass when taking a railway journey is almost incredible. They worry as to whether they will get to the station in time, and if their luggage will arrive safely at its destination, and a hundred other things as well.

We once heard a lady say-almost boastfully, she seemed proud of the fact-that she never slept a wink all night if she was a penny out in her household accounts. She did not say what happened if she was a halfpenny out. We can only presume, therefore, that in that case she slept for half the night.

With worries of this sort we have no sympathy. They can be overcome by an effort of will, and those who give way to them had better realise that they are not only bothering the people around them, but endangering their own nervous systems as well. For worry leads to worry. A mind that is addicted to them will always tend to distort things, making mountains out of molehills. Objects invariably loom larger in a fog. And of all troubles in this life there are none so 
hard to bear as imaginary ones. Many of us prefer to meet a burglar rather than a ghost. The troubles we dread rarely come. Yet the strain of thinking about them tends to precipitate other disasters. The man who is always on the look-out for orange peel is very liable to run his head against a lamp-post. If after that he is always thinking of lamp-posts, he is almost certain to slip on a piece of orange peel. And people who are constantly worrying about the future, and all the ills that it may bring with it, are inviting troubles, for they are frittering their energies instead of applying them to their work.

Worry is a potent factor in causing neurasthenia, and once that has come about the system is deprived of its resisting power and

Worry and laid open to disease. And neurasneurasthenia. thenics are singularly prone to forebodings. The state of the nervous system alters the circulation in the body to such an extent that it is apt to cause the feeling of illness, if not illness itself. Such people are liable to feel chilly or burning hot, even though their temperatures may be normal. Yet because of their sensations they feel certain that they are going to be ill, and the dread of this still further aggravates their nervous condition.

While worry brings on neurasthenia, the latter adds to worry. The whole process is like a snowball rolling down - a hill, increasing in size as it does so. All the more reason, therefore, why we should take every precaution to arrest it at the 
outset, by considering in what way worry can be prevented.

This can never be done by running away from responsibilities or difficulties of any sort. Such as they may be, we must face them.

How There are many people to-day, as to prevent in the ancient time, who sigh for worry. the wings of a dove that they may fly away and be at rest. Even if they got the wings, it is doubtful if they would bo much better off. In all probability they would find that they had gone farther only to fare worse.

Neither can worry be got rid of by sitting down and trying to make up our minds that we will not give way to it. The seasick man might as well command the waves to be still. We have little direct control over the nervous system, but we have a vast amount of influence over the movements of the body, which reacts in such a pronounced manner on the mind.

The man who walks and talks hurriedly or jerkily tends to think in like fashion. Those whose minds are in a fume and a

Body and fidget usually show it by fussing mind. about and behave generally in a restless manner. Let them force themselves to walk quietly and deliberately, and they will be surprised to find how quickly their minds follow suit and settle down into a steadier groove. And if they take care to speak in the same deliberate fashion at the same time, the good effect will be heightened. The movement of the 
limbs and of the lips react on the mind to a surprising extent.

If any should doubt what we have said as to the close connection between the body and the mind, let them try an experiment which was advocated many years ago by a celebrated psychologist. It consists in reading a comic book with the features contracted into a stern frown, and following this up by reading a pathetic one with the face relaxed into a broad grin. The result will convince them as to the truth of our previous statements.

Sometimes a man is worried to death on account of some event he is anticipating, a reply

to some letter he has sent, or the Anticipation. news of some appointment he is in for. Often under such circumstances he will pace up and down like a caged beast, until the nervous tension almost makes him ill. Try as he may, he cannot sit still. But he can do something equally efficacious, he can engage in some other occupation, keeping his hands and mind employed, instead of glancing continually at the clock or looking for the postman.

And sometimes people are beset by business until they scarcely know where to turn. Then it may be that they become so

Beset by agitated that they can do nothing work. to further the matter in hand. A man once consulted a doctor as to an experience that had befallen him on the previous evening. "At teatime," he said, "I 
found myself becoming anxious and worried as to the amount of work in front of me. And the harder I tried to get on with it the more obstinately my brain refused to act, and by bedtime I had got everything into a hopeless muddle."

The doctor told him that curiously enough he himself had had a similar experience the same evening, and just about the same time.

"And what did you do ?" the patient inquired, and was much astonished when the medical man replied, "Went out, had a couple of games of billiards, then came back and finished it all comfortably in a couple of hours."

When a man finds that his work is worrying him unduly, or when he is so overwhelmed by it that he cannot keep his mental equlibrium, the best thing he can do is to stop it for a time and have a rest or a change of some sort, even if it is only for a few minutes. It will facilitate the work in the long run, and will save the nervous system from an amount of wear and tear which may take days or weeks to put right again.

Unpunctuality and untidiness are responsible for a great amount of unnecessary worry. The man who is habitually late in the mornings is apt to find his work accumulate to such an extent that by the time he ought to be finishing his day's work he feels it has become a heavy burden upon his shoulders. And people who keep their desks in an untidy condition lose a vast amount of time, and harass themselves by having to search for things they should have been able to put their fingers on at once. 
Above all, let a man avoid stimulating his flagging brain by means of alcohol, or soothing it by the aid of drugs. Tobacco, Stimulants. however, is-in the writer's opinion at least--a boon to people of a worrying disposition. If used to excess, especially in the form of cigarettes, it may sap the nervous system, and lead to more worry than it is likely to prevent. Taken in moderation, and in its healthiest form, that of a pipe, it often proves of great benefit to tired nerves.

It is of the utmost importance for people who are subject to worry to pay every attention to the way in which they spend their Leisure time. leisure time. It is even more important in their case than in that of people who work too hard.

The effect of overwork is to cause fatigue. The mind has been kept too long in a certain groove, until it has become wearied Overwork from sheer exhaustion. Certain compared parts of the brain or the body are with worry. tired out for the time being. Such persons need recreation pure and simple. A pleasant game or a light novel is the best remedy for their fatigue, taking the mind out of the groove in which it has been confined.

The effect of worry, on the other hand, is to produce a state of restlessness, both of mind and body. The nervous system is in an irritable condition, and requires something that will steady it down. A game may only add excitement to the restlessness. The brain is acting in an 
irregular, discursive manner, and needs some method of treatment which will reduce it to order. And this can best be obtained by means of a quiet hobby. The overworked man is like a horse that has been plodding along all day in the shafts with a heavy weight behind it; a little freedom, perhaps a gallop round a field, will do it more good than anything else. The over-worried man is like a horse that has been plunging aimlessly around, excited and irritable: an hour's hard work between the shafts is what it needs.

Therefore, while the fatigued man requires recreation, the worried one will do better with some hobby that needs a certain

Worries and amount of concentration. The form hobbies. of hobby best suited to him depends on his tastes and capabilities. A celebrated physician once told me that when he found himself becoming worried he could quiet his mind most speedily by mathematical problems. They would do him far more good than any game or other form of recreation.

Many people, however, might find this too great a strain, for it is possible to be worried and tired at the same time, as we all know. Yet there are many hobbies which demand a certain amount of concentration without making too great a call on the mental faculties.

They may take up books on travel, for instance, and there is no more fascinating form of reading. Let them select some particular country, and read all they can find about it, its inhabitants and customs, until they are authorities on that 
subject. Or they may go in for history, studying some particular period, and read all the manuals and historical novels dealing with it. Continuity is a great point in any hobby ; it makes it not only more interesting, but there is the pleasure of knowing it is always there, waiting for them, without their having to consider what to take up next.

Or they may dip into such subjects as astronomy botany or a host of others. And these will do more than refresh the mind at the time. People of a worrying disposition are always restless and fidgety on a railway journey, but those who take an interest in such things as geology, flora and fauna will find plenty to occupy their minds with as they go along. Even railway embankments may be made a cinematograph of delight to the man who has studied land formations. And anyone who is interested in architecture need never fear the tedium of having to spend an hour or two in a strange town waiting for the next train.

Those who have a taste for poetry may consider themselves fortunate, for there is something in the harmony of words that has a specially beneficial effect on the worried mind. The rhythm, either of blank verse or rhyme, is excellently adapted for reducing the aimless wandering of an overwrought mind to a regular, steady running. Especially is this the case if people take the trouble to learn it by heart. For this acts as a kind of mental mastication, and the poetry is consequently absorbed and becomes a part of 
their very being. Then they are laying up for themselves a store of treasures which they may enjoy: at any moment. People who worry are always liable to be irritable when alone, and need something to counteract their moody tendencies.

A man of this type was so subject to irritability of this sort when he was dressing in the mornings that he invariably started the day badly. And a day that begins in this way is like a choir that starts on a wrong note, it is a difficult matter to get back to the right one again. This man, owing to his unfortunate habit, found it almost impossible to recover a harmonious frame of mind, until at last he hit upon the secret. $\mathrm{He}$ had become enamoured of the writings of a certain poet, and had begun to learn whole passages by heart. After that he found himself repeating these to himself when he got up in the morning, and it is no exaggeration to say that it altered his life. It gave him a good send-off for the day, and saved him from many a mistake and many a worry.

A hobby which combines hand and eye and brain is of great service to a flurried mind. Engineers, carpenters and all who are engaged in like occupations unconsciously acquire an orderly, methodical way of thinking.

As to what form of manual work people take up their individual tastes will decide, just as much as in the kind of reading they indulge in. If they have a faculty for art, they can take up painting or music. And when I say music, I mean practising it properly, not simply sitting 
down to the piano to improvise or wander from piece to piece. It is the steady practice which does the brain good.

Or they may prefer carpentry of wood carving, or preparing microscopic slides, than which there is no more absorbing hobby. There are scores of others, too, equally interesting.

Nothing, however trivial, is beneath our notice, if it will in any way mitigate this deadly habit of worrying, which has such a detrimental influence on the nervous system, and so often is responsible both for the starting-point and the climax of a breakdown. 


\section{CHAPTER XX.}

\section{THE STRONG MAN}

THE strength of a chain lies in its weakest link, and the measure of man's strength is that of the weak point in his constitution. What He may have the frame and muscle strength is. of a Sandow, but if he has a faulty valve in his heart, it is by that, and not by his muscular development, that his strength must be gauged. Even supposing that every organ in his body is sound, and he is possessed of great powers of endurance, he cannot be called strong if he is impairing his digestion by careless habits of eating and drinking, or endangering his nervous system by habitually keeping late hours and burning the candle at both ends, or laying up gout in store for himself by gourmandising or want of exercise.

No matter whether the weak spot be in the man's own system or in his mode of life, Nature will find it out as surely as the arrow found the heel of Achilles. It is on his weak points that he must stand or fall ; it is in these that the strain will manifest itself, in other words, that the breakdown will appear.

The aim of this book has been to prevent matters ever reaching this stage, to arrest them at the "outset. No sign, of all those I have 
indicated as pointing towards a breakdown, should be neglected. The time to take heed is when any man or woman finds that their powers of work are failing them, their nerves easily upset, or their minds assailed by an unreasonable dread of the future, or that in one or other of various ways they are not the people they were. It is better to slow down at the first danger signal than to run past one after another until we are pulled up with a crash.

The first thing, therefore, is to find out the weak points; take care of these, and the strong ones will look after themselves.

Find out The man who taps the wheels of the weak railway carriages does so in order points. to detect flaws; he passes by the sound wheels with indifference. And there is a simple way in which people may find out in which particulars they are going wrong. If they have taken the trouble to wade through this book, they may have noticed that certain paragraphs or chapters attracted their attention. It does not follow that they agreed with them, or thought them important at the time. It may be that they said (provided they were of the male gender) that they were " all nonsense," or that it was " a precious lot of fuss about nothing."

It does not matter what they said or thought. The point is that they said or thought something. For the fact that they did so was proof that the piece of writing in question forced itself upon their notice, and must therefore have had some special application to their own case; and if this 
has been so, let them pay particular heed to those paragraphs, or pages or chapters, whichever they may have been.

If the advice given is not in accordance with their own feelings, that fact does not detract from its value. Many of us, in looking back, have to acknowledge that most of the warnings and counsels which have proved of the greatest benefit in the long run, were unpalatable at the time. They were distasteful simply because we knew in our inmost hearts that we stood in need of them. Otherwise we should not have paid sufficient attention to them even to feel any resentment on the subject. There is a lot of meaning in the saying, "Greater truth, greater libel."

Especially does this apply to the question of exercise and rest. It is not hard, as a rule, to convince people that they are

Tempera- committing errors of diet, or getting ment. too little fresh air; but it is very different when we come to deal with these other matters. Few people like to be told that they should take more exercise, or rouse themselves to show more interest in things outside their ordinary routine of work. It sounds like an accusation of indolence.

Yet such resentment is slight compared with that of the men or women who have to be warned that they are wasting their energies by restlessness and worry or lack of recreation. These strenuous natures are apt to take umbrage at the fact of their work being interfered with. They do not 
realise that what we wish is that they may be enabled to do better work and more of it in the end.

When a medical man sees a patient he has to do more than diagnose the disease. Often it happens

that before he can find out what is

Man, know the matter, and certainly before he thyself. can treat it efficiently, he must discover what type of man or woman he is dealing with. Any coachman will tell you that before he can drive a horse well he must get to know the animal itself. For some are restless and excitable and need the curb, whilst others are lazy and require the use of the whip. And for all who wish to guide themselves in matters of health it is of the first importance that they should know their own temperaments.

It is said that people are always the last to hear any gossip or scandal about themselves. It is equally true that they are usually the last to observe any change in their health or dispositions. A person may be growing thinner, paler, and more tired looking, and yet be unaware of the fact. Much more does this apply to all the nervous symptoms and other peculiarities which denote that he is on the down-grade and gliding towards a breakdown. Yet if any such signs are pointed out to him by others, either by a medical man or some candid friend, the best thing he can do is to give full consideration to their opinion. Let health be preserved while it can. The day may come when it will be lost never to be regained.

Throughout this book we have laid stress on the 
influence of the body on the mind, and the importance of attending to its

Adjusting various functions in order to keep the mind. the nervous system healthy. Yet we must not overlook the other fact, viz. that we are gifted with a certain, even if limited, amount of control over the mind itself.

Some writers have told us, and quite rightly too, that we can cultivate a brighter outlook on the future. We are recommended to persuade ourselves that there is no season in the whole year so acceptable as the one that is just commencingno beauty like that of spring, no glory like that of summer, no time so welcome as autumn with its dying splendours. And when winter comes we can look forward to the delights of the cosy fireside, so much more sociable than the long, garish days of summer. Instead of which, too many of us dread the heat and the cold and a good many other things, that are never so bad when they come as we think they are going to be.

A little calm philosophy undoubtedly goes a long way towards negotiating many of the difficulties and anxieties with which we are all confronted at times. Yet it is impossible to acquire a cheerful, philosophical frame of mind unless the body, with its nervous system and various organs, is in a healthy condition. After all, the chief thing is to attend to its requirements.

When all is said and done, we come back to the 
elementary rules of health. It is around these that the whole question of breakThe secret downs hinges. On the observance of preventing of them depend both the prevention breakdowns. and cure of this condition. If they were always carried out, this dire calamity would rarely, if ever, happen. When once it has loomed ahead there is only one thing to be done. The man or woman who sees it threatening them must retrace their steps and get back to the place where they took the wrong turning. They must work their way back until they have regained the health and vigour, which they once enjoyed but forfeited through their neglect of those laws.

And this needs a vast amount of patience and perseverance. It is easier to slide down than to climb up again, and people may find their progress marred by many a set-back. Yet a backward step in an upward climb does not mean that we have rolled to the bottom of the hill again. Many a man is discouraged when, after months of patient striving, he finds one day that his symptoms have returned-his nervousness, his inability to tackle his work, his feeling of langour and debility, or whatever else it may be. He thinks that all his efforts have been of no avail, and that he might as well give up.

He need not lose heart, it is but a temporary lapse. In a few days he will find himself climbing up once more. And if he holds on bravely he will one day reach the summit, and enjoy to the full the health and strength and energy of his earlier 
years. He will then have obtained his reward in the possession of that treasure which is greater than wealth or fame.

We cannot do better than conclude with words penned by a discerning writer more than two centuries ago:-

" Health is that which makes your meat and drink both savoury and pleasant. It is that which makes your bed easy and your sleep refreshing; that revives your strength with the rising sun, and makes you rejoice to behold the light of another day. Health is that which fills up the uneven parts of your body, making it plump and comely; which makes your mind fertile, and preserves the vigour, verdure, and beauty of your youth. 'Tis that which makes the soul take delight in her mansion, and adorns your face with glowing colours. Good health takes no notice of heart, lungs, stomach or nerves. Indeed, it does not know that there are such things."

The most wonderful feature of perfect bealth is its blissful unconsciousness.

THE END. 

RETURN TO the circulation desk of any University of California Library or to the

NORTHERN REGIONAL LIBRARY FACILITY Bldg. 400, Richmond Field Station

University of California

Richmond, CA 94804-4698

\section{ALL BOOKS MAY BE RECALLED AFTER 7 DAYS}

- 2-month loans may be renewed by calling (510) 642-6753

- 1-year loans may be recharged by bringing books to NRLF

- Renewals and recharges may be made 4 days prior to due date.

DUE AS STAMPED BELOW

MAYO 02001 

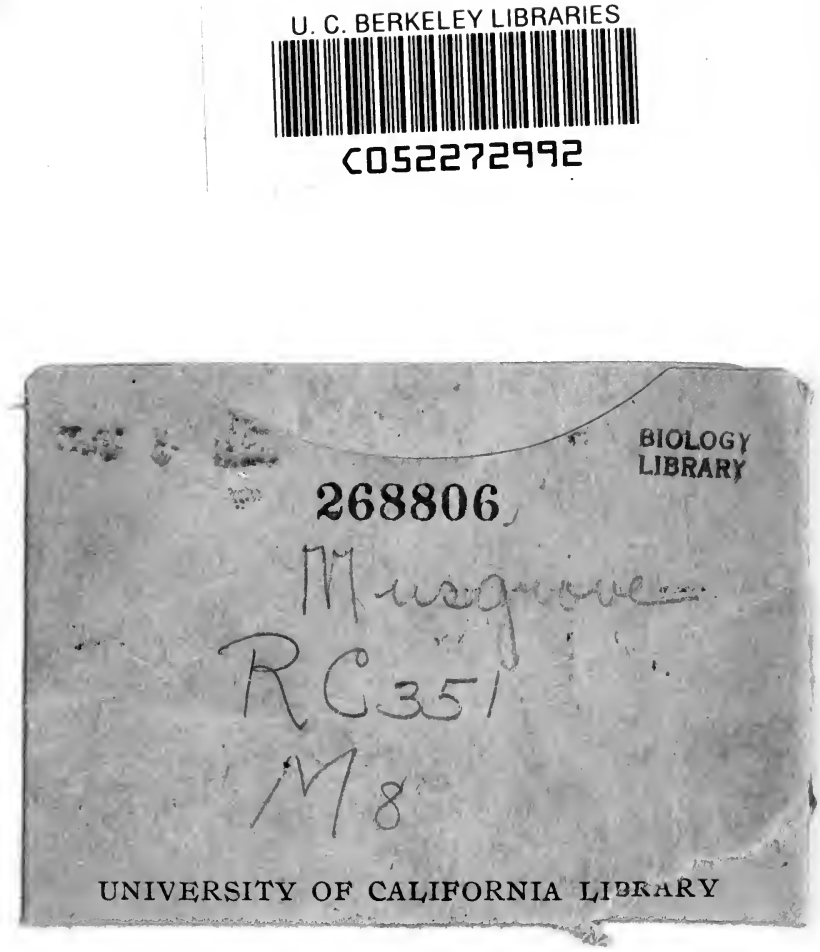
